\title{
MYOCARDIAL OXIDATIVE STRESS CHANGES DURING COMPENSATED RIGHT HEART FAILURE IN RATS
}

A Thesis Presented to the University of Manitoba

In Partial Fulfilment of the Requirement

For the Degree Of:

MASTER OF SCIENCE IN PHYSIOLOGY

By

JULIETA PICHARDO VELÁZQUEZ

Department of Physiology

Faculty of Medicine

July, 1997 
National Library of Canada

Acquisitions and Bibliographic Services

395 Wellington Street Ottawa ON K1A ONA Canada
Bibliothèque nationale du Canada

Acquisitions et services bibliographiques

395, ne Wellington

Otana ON K1A ONA

Canada

Your botere ritirence

Our fir Nome rithence

The author has granted a nonexclusive licence allowing the National Library of Canada to reproduce, loan, distribute or sell copies of this thesis in microform, paper or electronic formats.

The author retains ownership of the copyright in this thesis. Neither the thesis nor substantial extracts from it may be printed or otherwise reproduced without the author's permission.
L'auteur a accordé une licence non exclusive permettant à la Bibliothèque nationale du Canada de reproduire, prêter, distribuer ou vendre des copies de cette thèse sous la forme de microfiche/film, de reproduction sur papier ou sur format électronique.

L'auteur conserve la propriété du droit d'auteur qui protège cette thèse. $\mathrm{Ni}$ la thèse ni des extraits substantiels de celle-ci ne doivent être imprimés ou autrement reproduits sans son autorisation. 
THE UNIVERSITY OF MANITOBA

FACULTY OF GRADUATE STUDIES

COPYRIGHT PERMISSION

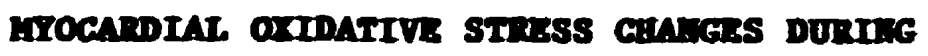

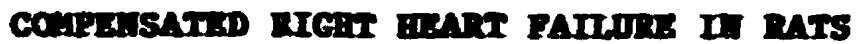

BY

JULIITA PIGaAmo VETKRQUEZ

A Thesis submitted to the Faculty of Graduate Studies of the University of Manitoba in partial fulfillment of the requirements of the degree of

MASTR of SCTHER

Julieta Pichardo Velazquez 1997

Permission has been granted to the LIBRARY OF THE UNIVERSITY OF MANITOBA to lend or sell copies of this thesis, to the NATIONAL LIBRARY OF CANADA to mierofilm this thesis and to lend or sell copies of the film, and to UNIVERSITY MICROFILMS to publish an abstract of this thesis.

This reproduction or copy of this thesis has been made available by authority of the copyright owner solely for the purpose of private study and research, and may only be reproduced and copied as permitted by copyright laws or with express written authorization from the copyright owner. 


\section{ACKNOWLEDGEMENTS}

I want to express my gratitude to Dr. Pawan $\mathrm{K}$. Singal for the patience and guidance throughout the course of my studies; without his advice, I wouldn't be here now.

My sincere thanks to Dr. Ian Dixon, Dr. Lorrie Kirshenbaum and Dr. Francis Amara, for their friendship and the time they spent reviewing this thesis: for their suggestions and support, thank you again.

To Dr. Thomas, who was always there to help me with any technical problem, and who took a lot of time to teach me what he knows.

I want to thank Dr. Vince Palace for his friendship, his guidance and the time he spent reading this thesis and many other things that I wrote, as well as for being such a wonderful person to work with.

A very special thank you to Diane Stowe, for being such a good friend and for being always willing to help when graphs and tables didn't turn out nicely.

I am also thankful to my friends Mike, Neelam, Natasha, Timao and Dr. Kumar for their unlimited support and friendship in good and bad times.

I want to thank the Government of Canada, Department of Foreign Affairs for the scholarship I received, and the Medical Research Council of Canada for the operating Grant that also supported me.

Finally, I want to thank Sergio, Tita, Paty and Bety. It was difficult for all of us to say good bye when I came in July, 1995. But they new better than me that I 
was able to go ahead with my studies, and that it was very important for me to have their smiles and support. I do not have enough words to express my gratitude to my family. A very special thanks to Jeff Werner, my best friend and my husband that has been near me in good and bad times, always there reminding me that I can go a little bit further. 
TABLE OF CONTENTS



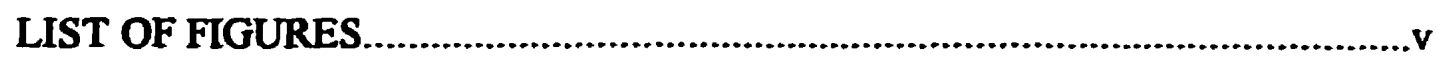

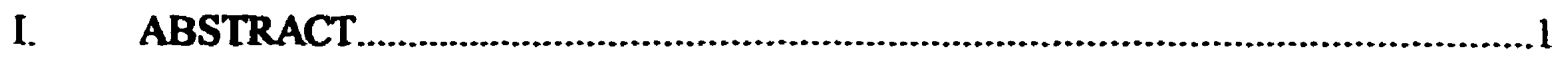

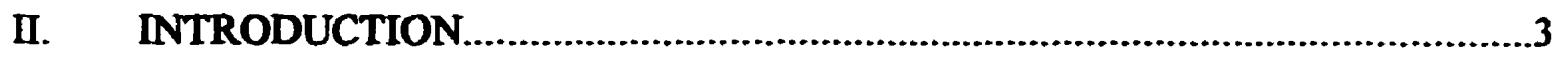



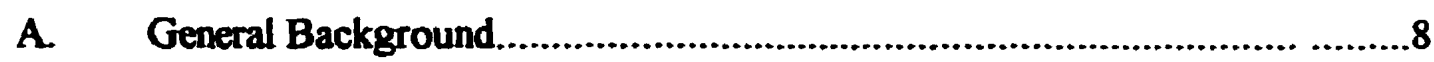

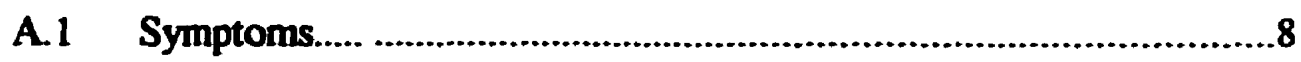

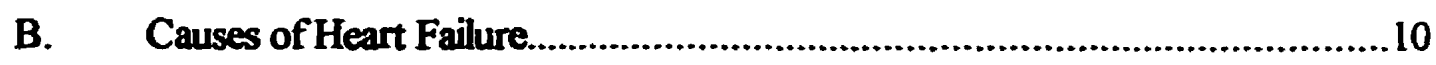

B.1 Myocardial Energy Production............................................ 10

B.2 Altered Ion Homeostasis......................................................... 11

B.3 Ventricular Remodelling .................................................12

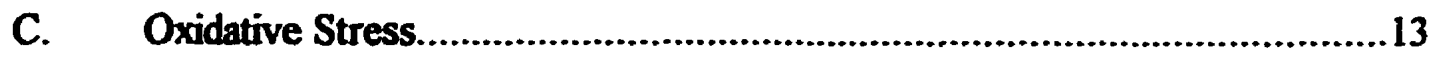

C.1 Antioxidant Defense Mechanisms.........................................14

C.2 Enzymatic Amtioxidants.................................................15

C.2.a. Superoxide Dismutase............................................15

C.2.b. Glutathione Peroxidase...........................................15

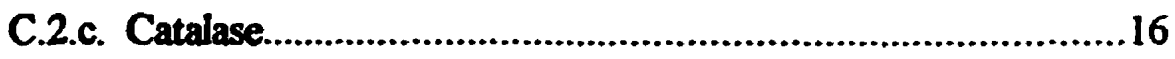

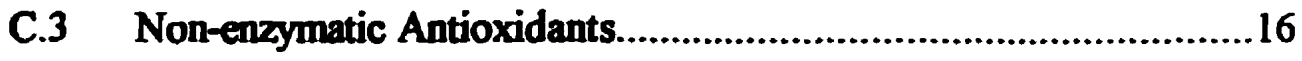




C.3.b. Ascorbic Acid and Glutathione..................................17

C.3.c. Other Antioxidants...................................................17

C.4 Oxidative Stress and Cardiovascular Pathologies........................18

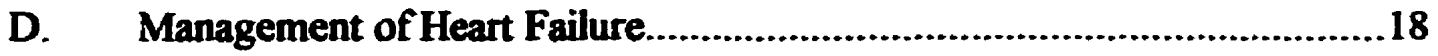

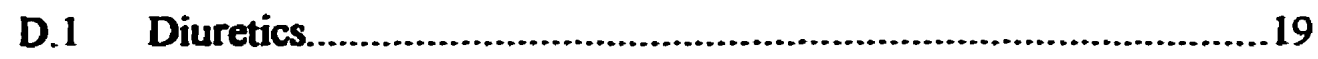

D.2 Cardiotonic Agents.........................................................

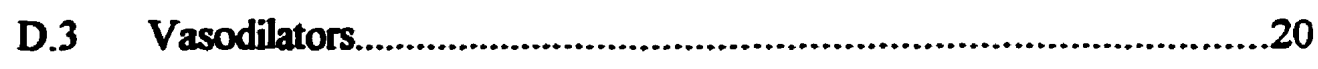





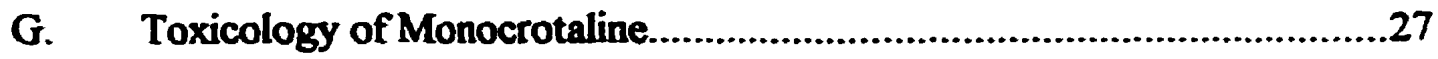

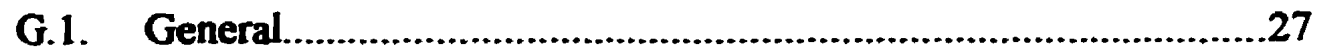

G.2. Pharmacology and Pharmacokinetics.....................................28

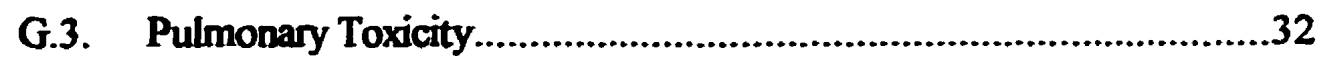

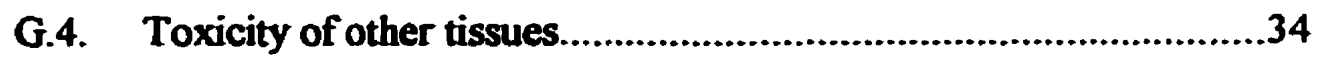

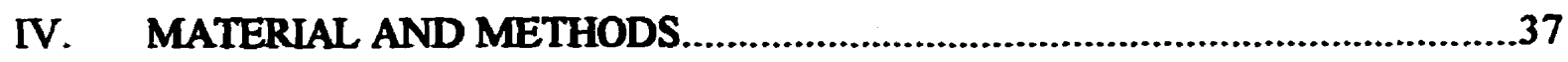

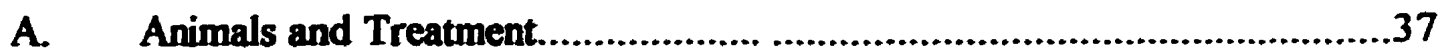

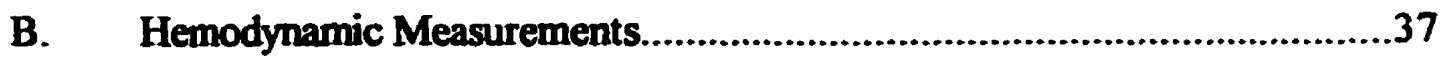

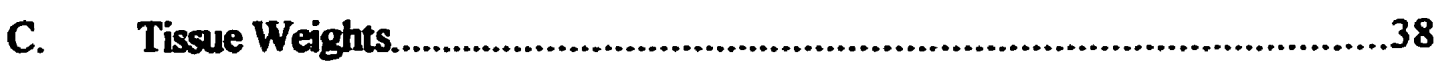

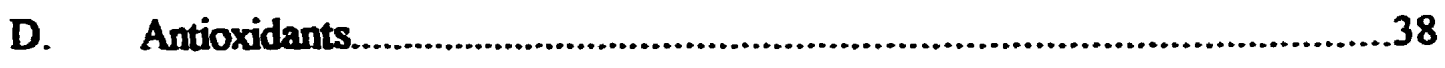



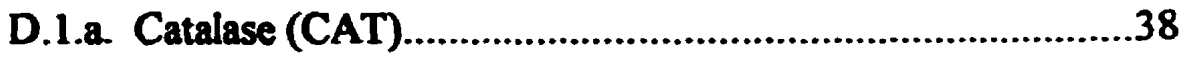

D. 1.b. Glutathione Peroxidase (GSHPx)................................39 
D.1.c. Superoxide Disumutase (SOD).......................................40

D.2. Non-enzymatic Antioxidants........................................................41

D.2.a. Extraction Procedure............................................................41

D.2.b. HPLC System

E. Lipid Hydroperoxides...............................................................................42

F. Statistical Analysis................................................................................43

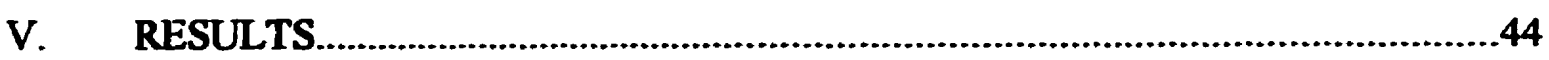

A. Body Weight and General Appearance.....................................................44

B. Assessment of Hypertrophy....................................................................44

C. Lung and Liver wet/dry Weight Ratio.........................................................46

D. Hemodynamic Changes.............................................................................46

E. Antioxidants

E.1 Enzymatic Antioxidants...........................................................50

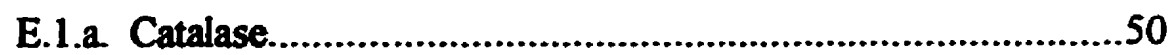

E.1.b. Glutathione Peroxidase......................................................50

E.1.c. Superoxide Dismutase...........................................................53

E.2 Non-enzymatic Antioxidants........................................................53

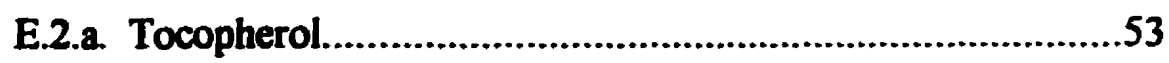

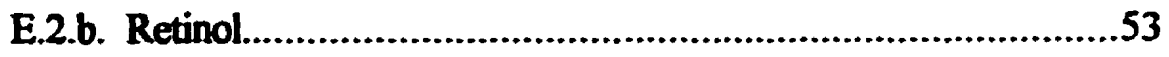

F. Lipid Hydroperoxides........................................................................57








\section{LIST OF TABLES}

Table

Page

Effects of monocrotaline on ventricular weights and ventricular to body weight ratio.

Effects of monocrotaline in wet to dry weight ratio in lung and liver.

3 Heart rate and right ventricular pressure changes in rats subsequent to monocrotaline injection. 


\section{LIST OF FIGURES}

Figure

Page

1 Monocrotaline metabolism in the liver.

29

Changes in body weight after monocrotaline or vehicle injection.

Catalase activity in right ventricles from control and monocrotaline treated rats.

Retinol concentration in right ventricle of control and monocrotaline treated rats. 


\section{ABSTRACT}

It has been reported that heart hypertrophy is accompanied by an increase in antioxidants and a decrease in oxidative stress, while the converse is true during heart failure. These conclusions are generally based on studies done on left heart failure. However, $14-34 \%$ of heart failure cases are due to an impairment of the right ventricular function and nothing is known about oxidative stress changes in this condition. In order to address this problem, oxidative stress changes were examined in the right ventricle of rats administered monocrotaline $(50 \mathrm{mg} / \mathrm{Kg}$ i.p.), a pyrrolizidine alkaloid known to produce pulmonary hypertension and right heart failure. Three weeks after the treatment, animals were assessed hemodynamically. The hearts were harvested and right ventricles were studied for enzymatic (catalase, glutathione peroxidase, superoxide dismutase) and non-enzymatic (vitamin E, retinol) antioxidant changes. Myocardial lipid hydroperoxides were also quantified in the right ventricle as a measure of overall oxidative stress.

Monocrotaline treatment resulted in reduced body weight gain and the treated animals were about $20 \%$ lighter than controls at 3 weeks post-treatment duration. These experimental animals showed signs of pulmonary distress manifested as shortness of breath, pallor and listlessness. In monocrotaline injected rats, right heart hypertrophy was confirmed by an almost 2 fold increase in ventricular weight. Both right ventricular systolic and end diastolic pressures were significantly increased, with a slight drop in heart rate. Lung as well as liver wet/dry weight ratios were unchanged in the monocrotaline group compared to the control. The occurrence of 
increased end diastolic pressure with a higher end systolic pressure in the right ventricle and no edema of the liver suggested that these animals were in a compensated right heart failure. An increase in the right ventricular weight to body weight ratio suggested the presence of hypertrophy in the right ventricle of experimental animals.

Myocardial antioxidant enzymes, catalase, glutathione peroxidase and superoxide dismutase in the right ventricle of monocrotaline treated rats were not different from the right ventricle of control animals. There were no differences with respect to the non-enzymatic antioxidant retinol. There was a significant decline in the vitamin $E$ content of the right ventricle of the monocrotaline treated animals. Lipid hydroperoxide concentrations in the right ventricle was three fold higher in the monocrotaline treated rats compared to the right ventricle of the control group.

These results suggest that during compensated heart failure the heart functions to produce elevated systolic pressures to maintain perfusion to vital tissues. However, at this elevated pressure there is an increase in oxidative stress and a decline in endogenous cardiac vitamin $E$ content. Other enzymatic and nonenzymatic antioxidants not being different from control raises the possibility that the changes may be biphasic, increasing in hypertrophy and decreasing in heart failure. Our investigation addressed the compensated heart failure stage. Increased oxidative stress seen in cardiac tissues in this study may precede overt heart failure in these animals and thus a time-course of changes need to be studied to confirm this aspect. Further studies are also required to understand the role of oxidative stress in the hypertrophic stage and period beyond the compensated right heart failure. 


\section{INTRODUCTION}

Congestive heart failure (CHF) affects 300,000 people in Canada annually (Liu 1996) and is a condition characterized by the inability of the heart to provide adequate blood flow to metabolizing tissues (Braunwald and Grossman 1992). A number of pathologies may impair myocardial contractility and thereby contribute to the development of CHF. These include structural abnormalities such as congenital malformations, valvular lesions, left ventricular aneurysm, coronary artery disease, myocardial infarction, diabetic cardiomyopathy, and cardiomyopathies resulting from cardiotoxic drugs.

Before the pathogenesis of heart failure, several adaptive mechanisms are triggered to maintain myocardial contractility during a relative increase in cardiac workload. Central to this compensation is the development of cardiac hypertrophy and augmentation of the mass of contractile tissue with or without chamber dilatation (Gerdes et al. 1996, Bassand 1995). Stimulation of the adrenergic (Hauser et al. 1996, Xiong et al. 1996, Anfossi and Trovati 1996, Kinugawa et al. 1996), and reninangiotensin-aldosterone systems, as well as other neurohumoral adjustments can act to maintain arterial pressure and thus perfusion to vital organs (Teerlink 1996, Kinugawa et al. 1996, Kato et al. 1996). Activation of the renin-angiotensinaldosterone system also increases fluid retention, which acts as a compensatory mechanism to maintain arterial blood pressure and cardiac output (Luchner et al. 1996). 
Transition from the adaptive changes of hypertrophy to the pathogenesis of CHF is known to be accompanied by different cellular and subcellular changes. During hypertrophy there is an increase in mitochondrial content (Morgan and Baker 1991) probably to meet the increased energy demand. However, as the muscle continues to hypertrophy the distance between the capillary blood flow and the cells also increases, as the capillary network is not able to develop as fast as the myocardium (Kobayashi et al. 1994). Therefore, during the development of heart failure, even though there is an increase in mitochondrial content, the ability to produce energy may be insufficient for the greater myocardial mass. Indeed in heart failure stage there is a relative decrease in the high energy phosphates.

Transition from hypertrophy to CHF has also been suggested to include the depletion of myocardial high energy phosphate stores, related to both mitochondrial deterioration and to a decrease in creatine phosphate flux to the myofibrils. Creatine Phosphate is an important factor in the energy transport in cardiomyocytes (Tian et al. 1996). Since myocardial cells preferentially use ATP that is supplied by regeneration through the creatine kinase reaction (Bessman et al. 1990).

A second important process in the transition from hypertrophy to CHF is the development of myocardial stiffness. Insufficient energy supply to the myofibrils and accumulation of products of adenine nucleotide breakdown can contribute to CHF by decreasing calcium sensitivity of myofibrils (Kapelko et al. 1996). This results in increased stiffness during the period of energy deprivation related to a decrease in the ATP:ADP ratio within the myofibril ( Kupriyanov et al. 1991). An increase in 
ADP and cytoplasmic $\mathrm{Ca}^{2+}$ (Allen and Orchard 1983) content can also contribute to stiffness by facilitating an increase in the number of actomyosin bonds remaining attached and sustained cross-bridge activation during diastole.

The pathogenesis of CHF may also involve alterations in ion homeostasis. In particular, intracellular $\mathrm{Ca}^{2+}$ can be increased several fold (Morgan and Baker 1993). This increase may exceed the capacity of the sarcoplasmic reticulum to take up $\mathrm{Ca}^{2+}$ causing $\mathrm{Ca}^{2+}$ overload in cardiac myocytes. As $\mathrm{Ca}^{2+}$ overload progresses, oscillation of extracellular $\mathrm{Ca}^{2+}$ occurs and an asynchronous contraction of the myocardium is observed (Saeki et al. 1993, Orchard et al. 1983). The $\mathrm{Na}^{+} / \mathrm{K}^{+}$ATPase has also been shown to be downregulated in the failing heart (Norgaard et al. 1990). This decreased activity can increase intracellular $\mathrm{Na}^{+}$which is normally exchanged for extracellular $\mathrm{Ca}^{2+}$, exacerbating $\mathrm{Ca}^{2+}$ overload.

Ventricular remodelling has also been considered as a factor contributing to the onset of CHF. Remodelling takes place in both viable myocardium and the dead tissue in response to myocardial infarction, where the necrosed myocardium is being replaced by fibrous scar tissue (von Krimpen et al. 1991). Meanwhile, viable myocardium inclusive of myocytes and non-myocytes, undergoes hypertrophy with some or all the aforementioned metabolic, ionic and biochemical changes in CHF. Finally, the transition from hypertrophy to CHF has historically been investigated with reference to energy demand and supply, ion homeostasis and ventricular remodelling processes. Over the last two decades, it has become increasingly clear that oxidative stress is of paramount importance in this process (Singal and 
Kirshenbaum 1990, Hill and Singal 1996, Hoffman and Garewal 1995).

Under normal conditions there is a continuous production of free radicals by various metabolic redox reactions. These reactive oxygen species are not problematic because they are converted to less reactive products by cellular antioxidant defense mechanisms that include enzymatic (CAT, GSHPx, SOD) and non-enzymatic (Vitamins E, A and C, glutathione) antioxidants (Singal et al. 1995). However, the condition known as oxidative stress arises when the production of free radicals overcomes the capacity of edogenous antioxidants (Hill and Singal 1996).

It is well known that an increase in oxidative stress is involved in various disease states. Heart failure, ischemia-reperfusion, aging, arthritis and several different types of cardiomyopathy ; all involve elevated free radicals generation. Additionally, different models have been developed to try to understand the role of oxidative stress in the above mentioned pathologies (Singal et al. 1995, Ferrari 1992).

Coronary artery ligation (Hill and Singal 1996), aortic banding, drug-induced cardiotoxicity (Siveski-Iliskovic et al. 1994), are some of the approaches currently being used to induce the development of heart failure so that the involvement of oxidative stress can be studied. It has been shown in these models that oxygen free radical production is significantly increased during the disease stage. Accompanying the increase in oxidative stress is a decrease in the antioxidant status of the myocardium (Singh et al. 1995). Before the disease stage, during hypertrophy, it has also been shown that there is an increase in the activity of antioxidant enzymes and a decrease in lipid peroxidation, whereas, during heart failure there is a marked 
increase in the generation of oxygen free radicals correlated with declining antioxidant status (Belch et al. 1991); in fact, the transition from hypertrophy to CHF also involves biphasic changes in the cellular antioxidant status and occurence of oxidative stress (Dhalla and Singal 1994). These antioxidant-oxidant dynamics have previously been described in left ventricular dysfunction but there is no information with respect to the right heart failure (RHF).

Fourteen to $34 \%$ of deaths related to heart failure in Canada are due to right ventricular failure (Liu 1996). Right heart failure develops as a consequence of an increase in ventricular afterload due to pulmonary embolism and hypertension (Rubin 1995). In order to address the experimental examination of RHF. monocrotaline treatment of small mammals has been used to induce pulmonary hypertension and subsequent induction of right ventricular hypertrophy and congestive failure. This model is advantageous because right heart hypertrophy and failure develop relatively quickly and reproducibly. With this approach the antioxidant-oxidant dynamics in the transition from hypertrophy to CHF was studied in rats to determine the role of oxidative stress during the development of right ventricular failure. 


\section{LITERATURE REVIEW}

\section{A. General Background.}

In Canada, about $40 \%$ of all deaths in the general pupulace are due to heart failure (Liu 1996). Congestive heart failure (CHF), a condition characterized by the inability of the heart to provide adequate blood flow to body tissues, can result from structural abnormalities including congenital malformations, valvular lesions, left ventricular aneurysm, myocardial infarction, coronary artery disease, diabetic cardiomyopathy or from exposure to cardiotoxic drugs. According to the New York Heart Association, there are four different stages of heart failure:

Class I No limitation in performing ordinary physical activity.

Class II Slight limitation. Ordinary physical activity results in dyspnea and fatigue. No symptoms at rest.

Class III Moderate limitation. Minimal physical activity produces dyspnea and fatigue.

Class IV Severe limitation. Symptoms of dyspnea and fatigue present at rest.

\section{A.1. Symptoms.}

Within this classification the main symptoms defining the occurrence of $\mathrm{CHF}$ are dyspnea and fatigue (Kleber and Wensel 1996). Dyspnea during left ventricular failure increases in its severity from exertional dyspnea, to orthopnea, paroxysmal nocturnal dyspnea, dyspnea at rest and finally acute pulmonary edema. These 
symptoms depend on the inability of the left ventricle to propel sufficient blood through the aorta, so that blood pools in the pulmonary circulation (Kleber and Wensel 1996). Fatigue, weakness and a feeling of heaviness in the limbs, are related to the accompanying decrease in skeletal muscle perfusion. Increased catecholamine release by the sympathetic nervous system acts to increase contractility and therefore cardiac output. Although this increase in the amount of blood expelled by the heart is distributed to provide adequate perfusion to vital organs, skeletal muscles receive less blood and fatigue arises (Simonini et al. 1996).

Other symptoms including confusion, headache, insomnia and delirium can be associated with heart failure. Additionally, pallor and coldness of the extremities and cyanosis of the digits results from an increase in adrenergic activity and peripheral vasoconstriction. Hydrothorax due to severe systemic venous hypertension and pulmonary embolism and ascites, due to an increase in capillary permeability are other symptoms frequently observed during severe heart failure.

During CHF there is a loss of myocardial contractility which is manifested in reduced cardiac output. Lower cardiac output then elicits renal responses including increased water and $\mathrm{Na}^{+}$retention and vasoconstriction that initially helps to maintain arterial blood pressure and tissue perfusion (Luchner et al 1996). Consequently, the earliest clinical signs of CHF are increases in $\mathrm{Na}^{+}$and water retention.

Aside from fluid and ion retention, other adaptive mechanisms are triggered to optimize perfusion of the body tissues. These include: a) development of cardiac 
hypertrophy with or without chamber dilatation to augment the mass of contractile tissue (Gerdes et al. 1996, Bassand 1995); b) an increase in the catecholamine release to increase myocardial contractility (Hauser et al. 1996, Xiong et al. 1996, Anfossi and Trovati 1996, Kinugawa et al. 1996); c) activation of the reninangiotensin-aldosterone pathway; and d) other neurohumoral systems to maintain blood and perfusion pressures (Teerlink 1996, Kinugawa et al. 1996, Kato et al. 1996).

Continued systematic studies of these adaptive mechanisms and the subsequent pathogenesis of CHF are greatly needed in order to fully understand the widespread existence of cardiovascular disease.

\section{B. Causes of Heart Failure.}

\section{B.1. Myocardial Energy Production.}

Disturbances in the normal production of energy are thought to be an important cause of heart failure. During hypertrophy there is an increase in mitochondrial content, mainly due to an increase in muscular mass. As the muscle hypertrophies, the distance between the capillaries and the cells increases because the capillary net cannot develop as fast as the growing myocardium. Therefore, during heart failure, the ability of the mitochondria to produce and supply energy is insufficient for the larger myocardium.

During contractile failure, low energy supply to the myofibrils can result in increased stiffness of the myocardium. Stiffness may be attributed to several factors, 
including enlargement of the myocytes, cardiac fibrosis, contracture of the sarcomeres in some cells, calcium retention in myofibrils and limited ATP supply to the myofibrils. Accumulation of adenine nucleotide breakdown products decrease calcium sensitivity of the myofibrils (Kapelko et al. 1996), can also contribute to stiffness during the period of energy deprivation (Kupriyanov et al. 1991). In fact, any increase in ADP versus ATP content can increase stiffness by raising the number of actomyosin bonds remaining attached during diastole. Elevation of cytoplasmic calcium (Allen and Orchard 1983) may induce sustained cross-bridge activation and also contribute to stiffiness.

The depletion of myocardial high energy phosphate stores may be related to both mitochondrial deterioration and to a decrease in creatine phosphate flux to the myofibrils, the main pathway for energy transport in cardiomyocytes (Tian et al. 1996). Compromised energy production in mitochondria is likely related to the gradual increase in cellular calcium during CHF (Dhalla et al. 1994, Tian et al. 1996). Since myocardial cells use ATP supplied by the creatine kinase reaction (Bessman et al. 1990), the decrease in the creatine kinase reaction velocity and contractile reserve seen in cardiomyopathic hearts, suggests that depletion of the energy reserve contributes to the development of heart failure (Tian et al. 1996).

\section{B.2. Altered ion homeostasis.}

Altered ion homeostasis is another central theory for explaining the progression of CHF. For example, under pathophysiological conditions intracellular 
$\mathrm{Ca}^{2+}$ concentration increases beyond the capacity of the sarcoplasmic reticulum to take up the ion, causing $\mathrm{Ca}^{2+}$ overload in cardiac myocytes. While $\mathrm{Ca}^{2+}$ overload progresses, oscillation of extracellular $\mathrm{Ca}^{2+}$ occurs and asynchronous contractions are observed (Saeki et al. 1993, Orchard et al. 1983). The ryanodine-sensitive $\mathrm{Ca}^{2+}$ release channels of the sarcoplasmic reticulum play a particularly important role in the intracellular $\mathrm{Ca}^{2+}$ handling in cardiomyocytes. Altered expression of ryanodine channel constituents contributes to abnormal cellular $\mathrm{Ca}^{2+}$ handling and myocardial dysfunction in dilated and ischemic cardiomyopathy (Schumacher et al. 1995). Other ion handling systems are also altered during the compensated failure stage. For example, the $\mathrm{Na}^{+} / \mathrm{K}^{+}$ATPase has been shown to be down regulated in the failing heart (Norgaard et al. 1990).

\section{B.3. Ventricular Remodelling.}

Ventricular remodelling, a third mechanism proposed to explain CHF, refers to the structural and biochemical changes that take place in response to volume overload and/or hypertension in the failing heart. This remodelling of the cardiac tissue is characterized by concentric and eccentric hypertrophy of the myocytes and alterations of the biochemical characteristics of the myosin protein (Mill et al. 1990). The process of remodelling subsequent to myocardial infarction involves necrosed myocardium being replaced by fibrous scar tissue (von Krimpen et al. 1991) as well as fibrosis of the extracellular matrix. Meanwhile, the viable myocardium undergoes hypertrophy, that may be accompanied by an increase in myocyte diameter or length 
or both. Lateral myocyte expansion is responsible for an increase in ventricular wall thickness without changing the chamber volume. In contrast, myocyte lengthening alone produces an enlargement of the chamber with a relative thinning of the wall (Olivetti et al. 1990).

\section{Oxidative Stress.}

Over the past two decades, attention has also been focused on oxidative stress as the main factor contributing to the progression of CHF. Oxidative stress is a condition that develops when cellular antioxidants are overcome by the production of oxygen free radicals. Free radicals are unstable and highly reactive chemical species that have an unpaired electron in their outermost orbital. The presence of an unpaired electron makes these radicals highly reactive.

Free radicals are continuously produced under normal conditions of aerobic metabolism. In fact, approximately $5 \%$ of all the $\mathrm{O}_{2}$ used during aerobic metabolism goes through univalent reduction pathway which generates oxygen free radicals (Singal et al 1988, Singal et al. 1995). The main generator of these chemical species' are the redox reactions. During aerobic metabolism, superoxide anions $\left(\mathrm{O}_{2}^{\left.-{ }^{-}\right)}\right.$are produced in the electron transport chain as by-products of various enzyme-substrate reactions, and by autoxidation of some low molecular weight molecules. In the heart, $75 \%$ of the superoxide generation occurs between the quinones and cytochrome by autoxidation of the semiquinones (Ferrari et al. 1991), in the mitochondrial inner membrane. The other $25 \%$ comes from other auto-oxidizable electron carriers of the 
mitochondrial inner membrane, including NADH dehydrogenase. Autoxidation of catecholamines has also been suggested to contribute in the production of free radicals (Singal et al. 1982).

Superoxide anions are dismutated to form hydrogen peroxide $\left(\mathrm{H}_{2} \mathrm{O}_{2}\right)$, by the enzyme superoxide dismutase (SOD). Mitochondria are particularly rich in Mn SOD, so most of $\mathrm{O}_{2}{ }^{--}$is enzymatically dismuted to $\mathrm{H}_{2} \mathrm{O}_{2}$ and $\mathrm{O}_{2}$. Peroxisomes which contain oxidases can generate $\mathrm{H}_{2} \mathrm{O}_{2}$ directly without the presence of $\mathrm{O}_{2}^{--}$. Although $\mathrm{H}_{2} \mathrm{O}_{2}$ is not itself a radical, it is often considered along with them, because of its ability to produce the hydroxyl radical (OH) through the interaction of $\mathrm{H}_{2} \mathrm{O}_{2}$ with $\mathrm{O}_{2}^{--}$- Hydroxyl radicals can also be formed by means of the electron transport mechanism that operates within the endoplasmic reticulum and the nuclear membranes. The hydroxyl radical is the most potent oxygen free radical by virtue of its short half life and indiscriminate reactivity with cellular components.

\section{C.1. Antioxidant Defense Mechanisms.}

Oxygen free radicals produced by metabolism do not normally damage cellular components. Instead, chemical compounds called antioxidants readily accommodate the unpaired electron of free radicals and neutralize them (O'Keefe et al. 1995). Neutralization can take place enzymatically by superoxide dismutase (SOD), glutathione peroxidase (GSHPx) and catalase (CAT), or non-enzymatically by vitamin E ( $\alpha$-tocopherol), vitamin C (ascorbic acid), vitamin A (retinol) or its provitamin forms, glutathione, ubiquinone, ceruloplasmin, uric acid, desferroxamine, 
metallothionein, and other low molecular weight scavengers.

\section{C.2. Enzymatic Antioxidants.}

\section{C.2.a. Superoxide dismutase.}

Superoxide dismutase is a metalloenzyme that catalyzes the dismutation of $\mathrm{O}_{2}$ to $\mathrm{H}_{2} \mathrm{O}_{2}$.

$$
\mathrm{O}_{2}^{+}+\mathrm{O}_{2}^{+}+2 \mathrm{H}^{+} \quad \rightarrow \quad \mathrm{H}_{2} \mathrm{O}_{2}+\mathrm{O}_{2}
$$

In mammalian cells there are several isoforms. One containing copper and zinc and is found in the cytosol, and the other that contains manganese, is predominantly found in mitochondria. A third isoform containing iron, is found in the cytoplasm of Escherichia coli.

\section{C.2.b. Glutathione peroxidase.}

After superoxide anions are dismuted by SOD, hydrogen peroxide is produced. As mentioned, this molecule is not a free radical but it can be damaging and is, therefore, reduced by the enzymatic antioxidant, glutathione peroxidase (GSHPx).

$$
\mathrm{GSH}+\mathrm{H}_{2} \mathrm{O}_{2} \rightarrow 2 \mathrm{GSSG}+2 \mathrm{H}_{2} \mathrm{O}
$$

GSHPx uses glutathione (GSH) as a substrate, forming oxidized glutathione (GSSG), water and/or an organic alcohol (Chance et al. 1979). Once glutathione is transformed to its oxidized form, it can be re-reduced by the NADPH dependent 
enzyme, glutathione reductase. Since the concentration of glutathione is the ratelimiting factor for glutathione peroxidase, maintenance of cellular glutathione stores is critical. In fact, changes in the glutathione redox status are used as a sensitive and accurate index of oxidative stress (Ferrari et al. 1992). This enzyme plays an important role in hydrolysing lipid peroxides and thus interrupting free radical chain reactions.

\section{C.2.c. Catalase.}

CAT is a hemeprotein that, like GSHPx serves to protect the cell against $\mathrm{H}_{2} \mathrm{O}_{2}$ accumulation. CAT uses $\mathrm{H}_{2} \mathrm{O}_{2}$ in a peroxidative reaction both as an oxidant and reductant to produce $\mathrm{H}_{2} \mathrm{O}$ and $\mathrm{O}_{2}$.

$$
2 \mathrm{H}_{2} \mathrm{O}_{2} \rightarrow 2 \mathrm{H}_{2} \mathrm{O}+\mathrm{O}_{2}
$$

Catalase is found in low concentrations in the myocardium, but is catalytically most important when the concentration of $\mathrm{H}_{2} \mathrm{O}_{2}$ reaches the milimolar range. For example when $\left[\mathrm{H}_{2} \mathrm{O}_{2}\right]$ is $10^{-9}$ to $10^{-7} \mathrm{M}$, glutathione peroxidase is the major antioxidant defense, but as the concentration rises, so does the importance of catalase.

\section{C.3. Non-enzymatic antioxidants.}

\section{C.3.a. Vitamin $E$}

Vitamin $\mathrm{E}$ is a family of isoprenoid molecules which include tocopherols and 
tocotrienols. Among these molecules, $\alpha$-tocopherol is the most widely recognized and studied. $\alpha$-Tocopherol is a lipophilic molecule found in virtually all lipid membranes. It reacts directly with lipid hydroperoxide radicals to produce membrane lipids and a slow reacting $\alpha$-tocopheroxy radical (Burton and Traber 1990).

$$
\alpha-\mathrm{TOH}+\mathrm{ROO} \rightarrow \alpha-\mathrm{TO}+\mathrm{ROOH}
$$

Lipid peroxidation is not likely to occur when $\alpha$-tocopherol is above a concentration threshold of one $\alpha$-tocopherol molecule per 500 to 1000 membrane lipid molecules (Sies and Murphy 1991, Kornbrust and Mavis 1980).

\section{C.3.b. Ascorbic acid and Glutathione.}

Ascorbic acid is an aqueous soluble molecule whose main action is to regenerate vitamin $\mathrm{E}$ form the $\alpha$-tocopheroxy radical. After interacting with the $\alpha$ tocopheroxy radical, the oxidized form of ascorbic acid, dehydroascorbic acid, is produced. Glutathione can re-reduce the oxidized dehydroascorbic acid or interact directly with $\alpha$-tocopherol to re-reduce that molecule (Leedle and Aust 1990).

\section{C.3.c. Other Antiaxidants.}

Other lipid and aqueous soluble antioxidants including vitamin $\mathrm{A}$ and its provitamin forms ( $\beta$-carotene, astaxanthines, canthaxanthin), ceruloplasmin, ubiquinone, metallothionein, uric acid, thionein and melatonin can quench free radicals. Other molecules have also been proposed to act as antioxidants, but their 
mechanisms of action are still poorly understood.

\section{C.4. Oxidative Stress and Cardiovascular pathologies.}

CHF increases the generation of free radicals and decreases the effectiveness of antioxidant defenses. The higher production of free radicals arises from an increase in polymorphonuclear leucocyte and prostaglandin concentrations (Belch et al. 1991, Parmley 1985), and autoxidation of the higher prevailing catecholamine concentration (Singal et al. 1982). Aditionally, during acute heart failure there is a decrease in antioxidant enzyme activity (Hill and Singal 1996). However, prior to this, during the hypertrophic phase of heart failure, there may actually be an increase in the antioxidant capacity of hearts subjected to pressure overload (Gupta and Singal 1989, Singh et al. 1995, Kaul et al. 1993, Dhalla and Singal 1996). Strong evidence also points to the involvement of oxygen free radicals in the development of reperfusion injury (Grech et al. 1995, Singh et al. 1996). Numerous studies report the potential benefit for administering antioxidants to reduce the deleterious effects free radicals during reperfusion (Kirshenbaum and Singal 1992, Kirshenbaum and Singal 1993, Bernier et al. 1986, Bell et al. 1990).

\section{Management of Heart Failure.}

Current treatments for heart failure entail different methods to decrease the workload of the heart, improve cardiac contractility, and reduce sodium and water retention. 


\section{D.1. Diuretics.}

To reduce the workload imposed on the heart, diuretics, are often used. These drugs act on the kidney to induce a decrease in salt and fluid retention, that in turn decreases blood volume to reduce the afterload. Often, low-dose diuretic therapy is effective in preventing both stroke and coronary related events (Freis and Papademetriou 1996). Diuretics are effective in improving congestion and decreasing ventricular filling pressures (Kleber and Wensel 1996). Differences between diuretics lie in their sites of action. Loop diuretics reduce cation transport by inhibiting the $\mathrm{Na}^{+} / \mathrm{K}^{+} / \mathrm{Cl}^{-}$co-transporter, and can induce natriuresis of up to $20 \%$ of the filtered load of sodium in a short period of time (Yelton et al. 1995). Distal tubule diuretics, or thiazides, inhibit resorption of $\mathrm{NaCl}$ in the distal tube. These compounds also promote calcium resorption by enhancing the entry of calcium into the distal tubular epithelial cells.

\section{D.2. Cardiotonic Agents.}

Cardiac glycosides have also been widely used in the treatment of CHF. Cardiac glycosides generally improve depressed myocardial contractility, increase cardiac output, promote diuresis and reduce the filling pressure of the failing ventricle, with the consequent reduction of pulmonary vascular congestion (van Veldhuisen et al. 1996). The most commonly used glycoside is digitalis. It has a positive inotropic action, increasing the force and velocity of contraction in the failing heart through the inhibition of the $\mathrm{Na}^{+} / \mathrm{K}^{+}$ATPase. Inhibition of the ATPase pump 
induces a net loss of $\mathrm{K}^{+}$and a net uptake of $\mathrm{Na}^{+}$. This $\mathrm{Na}^{+}$uptake by activation of the $\mathrm{Na}^{+} / \mathrm{Ca}^{2+}$ exchanger increases the intracellular $\mathrm{Ca}^{2+}$ concentration, and thereby increases contractility (McMahon et al. 1996).

While glycosides are beneficial in the treatment of patients with heart failure. they also have some toxic effects. The administered dose must be adjusted according to the susceptibility of each patient and monitored constantly to avoid toxicity. Major manifestations of toxicity include arrhythmias, disturbances of cardiac refractory period (ventricular bigemy, trigemy, tachycardia), gastrointestinal (anorexia, nausea, vomiting) and central nervous system symptoms (headache, fatigue disorientation, confusion, delirium, seizures).

Catecholamines and other sympathomimetic amines exert potent inotropic effect by interacting with myocardial $\beta$-adrenoceptors, but they also have potent positive chronotropic effects which are non desirable effects in patients with heart failure (Xiong et al. 1996, Hauser et al. 1996). Epinephrine causes tachycardia and hypotension by stimulating $\boldsymbol{\beta}_{1}$-adrenoceptors in the sinoatrial node and $\boldsymbol{\beta}_{2}$-receptors in the systemic vascular bed. Norepinephrine, a powerful stimulant of $\beta_{1}$ and $\alpha_{1}$ adrenoceptors, causes vasoconstriction and hypertension (Heilbron and Gin 1996). Dopamine and dobutamine cause less tachycardia and fewer systemic vascular effects, so they are of some use in short term treatment of severe heart failure.

\section{D.3. Vasodilators.}

In patients with congestive heart failure, the arterial and venous beds are often 
constricted. Vasoconstriction is due to a decrease in cardiac output, that acts to up regulate adrenergically mediated vasoconstriction tone. Circulating catecholamines, renin, and, therefore, angiotensin II and arginine-vasopressin, levels are all increased. Thicknesses of arteriolar walls are also elevated due to the accumulation of extracellular fluid in the blood vessels. Therefore, vasodilator drug therapy for $\mathrm{CHF}$ is common.

In general, vasodilators do not exert a direct effect on myocardium, but instead relax vascular smooth muscle cells resulting in improved hemodynamics of the patient. Arteriolar dilation reduces afterload and augments cardiac output, while venodilators reduce preload to lower ventricular filling pressure, and reduce the symptoms of pulmonary congestion (Kleber and Wensel 1996).

In CHF patients who have elevated levels of renin, angiotensin and aldosterone, angiotensin converting enzyme (ACE) inhibitors are often used. ACE inhibitors depress circulating and local levels of angiotensin II, a strong vasoconstrictor but conversely, angiotensin I levels increase. $\mathrm{ACE}$ inhibition also modulates the breakdown of bradykinin, thereby increasing circulating levels of this vasodilator (Kiowski et al. 1996, Teerlink 1996). ACE inhibitors also cause a decline in left and right ventricular filling pressures and a slight increase in cardiac output with no change to arterial pressure or heart rate (Struthers 1996).

Other vasodilators used are nitrate derivatives, hydralazine and the calcium antagonists. These compounds act principally on the vascular smooth muscle layer. Nitrates have prominent venodilation capabilities and act in the pulmonary and the 
systemic arteriolar beds. CHF patients with elevated pulmonary capillary pressure are often successfully treated with nitroglycerin to reduce ventricular filling pressure and relieve congestive symptoms (Munzel et al. 1996). Conversely, hydralazine acts directly on arteriolar smooth muscle, resulting in an increase of cardiac output with relatively minor reductions in ventricular filling and arterial pressure (Munzel et al. 1996). The calcium antagonists, nifedipine, diltiazem and dehydropyridine are variably use in the treatment of patients with heart failure (Freis and Papademetriou 1996), and yield only short term improvement of left ventricular function.

\section{E. Right Heart Failure.}

The bulk of studies examining the mechanisms, progression and treatment of CHF have been performed concerning the left ventricular function. This includes almost all of the studies examining oxidative stress as a fundamental factor in the pathogenesis of CHF. It is known that heart failure accounts for $40 \%$ of the deaths in Canada, however, it is important to recognize that 14 to $34 \%$ of these are due to right ventricular failure.

Right heart failure (RHF) develops as a consequence of an increase in ventricular afterload due to pulmonary embolism and hypertension (Kirshbom et al. 1996, Shimoni et al. 1996). Pulmonary hypertension is most often defined by a resting pulmonary arterial pressure greater than 35 to $40 \mathrm{mmHg}$ compared to approximately $28 \mathrm{mmHg}$ in normal individuals (Tak et al. 1996, Lualdi and Goldhaber 1995). Once established, pulmonary hypertension leads to right 
ventricular hypertrophy which may ultimately result in failure. A decrease in coronary perfusion pressure to the overloaded right ventricle may produce ischemia and exacerbate RHF.

Right heart failure is characterized by the presence of ascites, hydrothorax. increased pulmonary pressure, shortness of breath, jugular venous distention, systemic hypotension, hepatomegaly, peripheral edema, dyspnea on exertion, fatigue and angina. Angina is due to right ventricular ischemia secondary to an increase in myocardial oxygen demand, provoked by an increase in ventricular wall tension.

Many studies on the development of RHF, have shown similarities in changes seen in left ventricular failure. Specifically, norepinephrine concentration in the right ventricular free wall of animals with RHF increase (Angoletti et al. 1990, Ceconi et al. 1989) as does the concentration of epinephrine (Honda et al. 1991). Plasma levels of norepinephrine are also increased during RHF (Ishikawa et al. 1991). Okumura et al. (1995) showed a depletion of 1,2-DAG, NE and ACh with the progression of right heart failure but $\mathrm{NE}$ concentration was maintained during the development of hypertrophy. When these animals reached the failure stage there was a significant loss in NE concentration, and ACh concentrations varied in a similar way.

Plasma concentration of ANP is increased in patients and rats with CHF (Comini et al. 1995) and the peptide concentration in the right atrium decreased in relation to the severity of the disease. It was speculated that depletion of ANP may be due to the chronic stretching of the atrium as a consequence of right ventricular overload. Atrial natriuretic factor in rats with RHF decreased by $30.5 \%$ in the left 
atrium, and by $84.8 \%$ in the right atrium, whereas the concentration of ANP in the plasma increased 7.6 times. These changes are likely due to an increase in the rate of release of the peptide from the atria to the plasma leading to a decline in right and left atrial stores of ANF (Angoletti et al. 1990, Kuchel et al. 1987). Elevated ANF release may be mediated by adrenergic stimuli during cardiac failure to counterbalance the vasoconstrictor effects of the sympathetic nervous system and water retention by the renin angiotensin system (Packer 1988, Comini et al. 1995). In pigs, ANF, ICAM-1 (intracellular adhesion molecule-1), TGF $\beta$ (Tumor growth factor- $\beta$ ) and VEGF (vascular endothelial growth factor) were all increased in response to right ventricular pressure overload, but PDGF (platelet derived growth factor) was decreased (Carroll et al. 1995).

Several enzyme activities are suppressed during RHF. Similar to changes in the left ventricle, the $\mathrm{Na}+/ \mathrm{K}+\mathrm{ATPase}$ activity in the $\mathrm{RV}$ of animals with $\mathrm{RHF}$ is significantly decreased (Yoshie et al. 1994). Furthermore, the $\beta$-adrenoceptor density and adenylate cyclase activities were significantly decreased in the RV of rats in overt heart failure stage. The creatine kinase and lactate dehydrogenase activities were lower in animals that showed symptoms of RHF and isoenzyme distribution of the enzymes switched to the embryonal type of creatine kinase (CK-B) and to the anaerobic type subunit of lactate dehydrogenase (LD-M). These changes are thought to be adaptive for the failing heart condition (Ishikawa et al. 1995).

There is a shift from V1 to V3 myosin isoenzymes, and this change correlated with slower but more efficient myocardial contraction in right heart failure. Total 
collagen content increased with an increase of type II and type V collagen and a decrease in type I collagen. It is important to note that type II collagen is normally associated only with embryonic and neonatal development. Organ hypertrophy and/or hyperplasia have also been associated with type $\mathrm{V}$ collagen (Morioka et al. 1992, Ishikawa et al. 1994).

Although there bas been a recent surge in mechanistic studies concerning RHF and the trend is encouraging, these still represents a disproportionately small fraction compared with the number of clinically documented cases of RHF vs left heart failure. More work concerning the pathogenesis of RHF is required if we are to make a significant effect on the morbidity and mortality due to RHF.

\section{F. Models for studying Right Heart Failure.}

Several models have been used to experimentally induce right heart failure. In an earlier attempt, animals have been exposed to anoxemic conditions, in a steel respiratory chamber kept at lower pressure (Van Liere 1936). Under these conditions, there was an increase in the heart weight/body weight ratio of rats by $155.8 \%$ the normal value and the difference was predominantly due to hypertrophy of the RV. Guinea pigs subjected to simulated atmospheric conditions of 18,000 feet in a steel tank, showed right ventricular hypertrophy (Valdivia 1957). In another model, rats kept breathing at a low oxygen pressure, had right ventricular hypertrophy shown by an increase of $80 \%$ in the $\mathrm{RV} /(\mathrm{LV}+\mathrm{S})$ ratio (Roberts et al. 1995). In response to chronic hypoxia in these rats, smooth muscle cells of the 
pulmonary vessel wall showed hypertrophy and/or hyperplasia and cell proliferation in the wall of peripheral arteries was also seen. In humans, pulmonary vascular remodelling with RV hypertrophy also occurs at high altitudes (Arias-Stella and Saldana 1962). This phenomenon can be reproduced in newborn rats continuously breathing gases with reduced oxygen tension for several weeks (Mayrick and Reid 1981, Rabinovithch et al. 1981).

Banding of the pulmonary artery to induce RV pressure overload is one of the most common models of induction for right ventricular hypertrophy ( $\mathrm{Ng}$ et al. 1995). Briefly, rats are anaesthetized and through a left thoracotomy, the pulmonary artery is exposed. After dissecting it from the aorta, a sterile silk suture is placed around the pulmonary artery and a blunt needle with a specified diameter is tied against the pulmonary artery. The needle is later removed resulting in a tied constriction of the artery to the size of the diameter of the needle (Roberts et al. 1995). Fifteen weeks after the surgery, rats showed cardiac hypertrophy with an elevation of the central venous pressure, evidence of fluid retention in the thoracic cavity and peripheral edema.

Another model for inducing right heart hypertrophy is the treatment of the rats with monocrotaline. This pyrrolizidine alkaloid predictably induces right heart failure, four weeks after the administration of monocrotaline. The chemical can be administered by an i.p. injection, dissolved in drinking water, or by mixing seeds of its plant of origin, Crotalaria spectabilis, in the food (Turner and Lalich 1965). A dose of $50-60 \mathrm{mg} / \mathrm{Kg}$ body weight of monocrotaline by i.p. injection is commonly 
administered. Intraperitoneal administration is an ideal approach in controlling the amount given as well as only one injection of monocrotaline is required. Animals always develop RHF in four weeks, and surgical interventions are avoided. Consequently, in each study a greater number of animals can be obtained in a reliable and reproducible fashion.

\section{G. Toxicology of Monocrotaline.}

\section{G.1. General.}

Pyrrolizidine alkaloids comprise a major group of toxins derived from plants. Crotalaria is a genus in the Leguminosae family found worldwide (Yan and Huxtable 1995). Several hundred species are known, many of which contain the pyrrolizidine alkaloid, monocrotaline (Smith and Culvenor 1981, Chesney and Allen 1973). These plants are botanically and geographically widespread and are responsible for considerable livestock loss. Outbreaks of poisoning as a result of contamination of grains by pyrrolizidine-containing weeds have occurred in Afghanistan, Uzbekistan, Tadjikistan, India and South Africa (Yan and Huxtable 1995). Poisonings from use of pyrrolizidine-containing plants as food or herbs have occurred in Saudi Arabia, Egypt, Europe, Britain, the Caribbean nations, Hong Kong, North America, and else where (Yan and Huxtable 1995b). They also represent a major public bealth and economic problem in both developed and underdeveloped countries (Smith and Culvenor 1981, Yan and Huxtable 1995).

In humans, pyrrolizidines cause hepatomegaly, veno-occlusive disease of the 
liver, cirrhosis (Lame et al. 1991, Yan and Huxtable 1995) and are considered to be liver carcinogens (Hirono 1981). Toxicity can also be expressed in other organ systems including the heart, lungs and central nervous system.

\section{G.2. Pharmacology and Pharmacokinetics.}

It is now known that the toxicity of monocrotaline is due to bioactivation in the liver (Yan and Huxtable 1995). There are two major routes of monocrotaline metabolism (Fig 1); 1) The $\mathrm{N}$-oxidation to monocrotaline $\mathrm{N}$-oxide via flavin monooxygenase (Lafranconi et al. 1985, Estep et al. 1991); and 2) The dehydrogenation to dehydromonocrotaline by means of P450-mediated dehydrogenation (Lame et al. 1991, Williams et al. 1989).

The first route is without toxicological implications, as $\mathbf{N}$-oxides appear to be toxic only if reduction to the parental alkaloid takes place (Yan and Huxtable 1995b). However, dehydromonocrotaline formed in the liver has four pathways available (Fig 2): 1) Hydrolysis to 6,7-dihydro-7-hydroxy-1,1-hydroxymethyl-5H-pyrrolizine (DPH), a compound of low toxicity (Lame et al. 1991, Yan and Huxtable 1995); 2) Alkylation of cell macromolecules, thought to lead to liver damage (Culvenor et al. 1962); 3) Dehydromonocrotaline can also be released into the circulation leading to damage of the hepatic vasculature. Once released into the circulation, this compound is able to travel to the pulmonary circulation where it exerts damage in this tissue leading to pulmonary hypertension (Lafranconi and Huxtable 1981); and

4) Conjugation with glutathione (GSH) to form 7-glutathionyl-6,7-dihydro-1- 


\section{Monocrotaline}



Dehydrogenalion mediated by cytochrome P450

Dehydromonocrotaline<smiles>CC(C)C(C)(O)C(=O)OCc1ccn2c1C(OC(=O)OC1(C)CCCC1)CC2</smiles>

Figure 1: Monocrotaline metabolism in the liver. 
1) RELEASE INTO THE CIRCULATION hepatic vascular damage -damage in other tissues
2) ALKYLATION

OF CELL

MACROMOLECULES

Proteins and nucleic acids

-liver damage


Dehydromonocrotaline



3) METABOLIZED TO DHP [6,7dihydro-7-dihydroxy-1,1=hydroxymethyl-5H-pyrrolizine] tess toxic

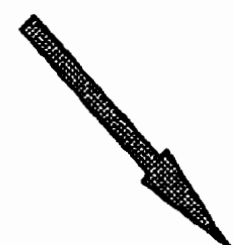

4) CONJUGATION WITH GLUTATHIONE Forms GSDHP [7glutathionyl- 6,7-dihydro-1hydroxymethyl-5Hpyrrolizine] which is excreted via the bile

Figure 2: Metabolism of dehydromonocrotaline 
hydroxymethyl-5H-pyrrolizine (GSDHP) which is released into the bile (Mattocks et al. 1991, Yan and Huxtable 1995).

The distribution of dehydromonocrotaline among these pathways determines both the sites at which toxicity is expressed as well as the degree of monocrotaline toxicity (Yan and Huxtable 1995). Monocrotaline pyrrole, is extremely reactive in aqueous solution (including plasma) with a half-life ranging from 3 to 5 seconds (Pan et al. 1993). It has been proposed that red blood cells could sequester monocrotaline pyrroles and reduce their aqueous degradation, while increasing their transport to lungs and other organs (Estep et al. 1991, Pan et al. 1993).

Monocrotaline given by single intraperitoneal injection is pneumotoxic in the range of 180-320 $\mu \mathrm{mol} / \mathrm{Kg}$ (Altiere et al. 1986, Yan and Huxtable 1995). Given subacutely in drinking water, however, monocrotaline exhibits pneumotoxicity in the range of only $30-40 \mu \mathrm{mol} / \mathrm{Kg}$ (Shubat et al. 1989). Of the pyrrole forms of monocrotaline, DHP (Fig. 2) shows extra hepatic toxicity only at doses of 350 $\mu \mathrm{mol} / \mathrm{Kg}$ or higher, whether given subcutaneously, intraperitoneally, or via intravenous routes (Huxtable 1990). Dehydromonocrotaline, on the other hand, shows no systemic toxicity on subcutaneous injection (reacting completely at the site of injection) but shows toxicity with intravenous injection at a dose of $15 \mu \mathrm{mol} / \mathrm{Kg}$ (Bruner et al. 1983).

In feeding experiments which extend over three to four weeks, seeds of Crotalaria spectabilis were administered in diet at $10 \mathrm{mg} / \mathrm{Kg}$ to rats (Turner and Lalich 1965). At this dose pneumotoxicity is apparent at 4 weeks. It is important to 
note that a large portion of the original dose administered to animals is eliminated in the urine, a further $12 \%$ is lost in the bile, and only $25 \%$ is ultimately pneumotoxic (Estep et al. 1991).

Signs of monocrotaline toxicity include: tachypnea and dyspnea on excitement or at rest, peripheral cyanosis, weakness, listlessness, diarrhea, pale feces and marked fluctuations in weight (Hayashi and Lalich 1967). Sudden weight gain is as significant as weight loss, since it reflects the accumulation of edema and fluid effusions from the serous cavities (Pan and Huxtable 1993, Angoletti et al. 1990, Turner and Lalich 1965).

\section{G.3. Pulmonary Toxicity:}

Early pulmonary changes in rats treated with monocrotaline are acute congestion, pulmonary edema and intra-alveolar hemorrhage. These changes result in alveolar hypoventilation and hypoxia which are known to produce pulmonary hypertension probably by means of arterial vasoconstriction (Boor et al. 1994). Capillary occlusions, arteriolar hyalinosis, and the thickening in the walls of both the muscular and elastic arteries are all evidence of an increased pulmonary vascular resistance, that induce right ventricular hypertrophy (Todorovich-Hunter et al. 1992 , Boor et al. 1994). The hypertrophy and dilation is limited to the right ventricle (Kentera et al. 1978). Histological examination reveals small foci of myocardial degeneration in the right ventricle or septum, and focal lymphocytic infiltration (Valdivia 1957). 
Macroscopic examination of the lungs, reveals that they are bulky, edematous. congested, haemorrhagic foci and areas of induration are also evident (Shultze et al. 1994). Microscopic sectioning of the lungs show nodules (Turner and Lalich 1965), congested capillaries, and in some areas they have ruptured into the alveolar sacs where free erythrocytes and siderophages are present along with the fibrinous edema fluid. Intense eosinophilia with swelling of the endothelial lining and occlusion of the lumen by fibrin and enmeshed erythrocytes also occurs (Roth et al. 1981, Allen et al. 1972). Inflammatory cell infiltration surrounding the occluded capillaries, interstitial and intra-alveolar fibrosis with emphysema, distorted lung structure, prominent and thickened vessels of arteriolar calibre and the presence of a layer of smooth muscle cells outside the elastic membrane, occasionally showing necrosis are present (Pan et al. 1993). The internal elastic lamina, which normally separates endothelial cells from the smooth muscle cells in muscular arteries is often fragmented (Zhu et al. 1994) and in some instances endothelial cell proliferation has resulted in complete obstruction of the arteriole. More commonly fibrin occlusions are present (Turner and Lalich 1965). Endothelial cells of the intima and fibrin thrombi form on the damaged intimal surface. In the reparative process, the media is replaced by fibrous tissue and fine elastic fibres are without normal orientation (Turner and Lalich 1965). The end result of all these changes in the pulmonary vasculature is increased resistance to $R V$ output.

In some arteries, hypertrophy and hyperplasia of the muscle coat, as well as hypertrophy of the endothelial cells results in disruption of the endothelium and 
accumulation of large amounts of fibrin, blood cells and plasma in the subendothelial area and between the muscular components of the vessel. This can result in complete or partial occlusion of the vessel lumen (Allen et al. 1972). Additionally, the fibrin is covered with an endothelial lining and the end result is a grossly thickened intima with fibroelastosis. The walls of arteries become thicker, and the lumen is sometimes reduced to a mere slit (Pan et al. 1993). Other relevant damage includes a thickening of the alveolar septa that is associated with the loss of pulmonary capillaries (Boor et al. 1994) and abnormal muscularization of normally non muscular peripheral arteries as a result of differentiation of precursor cells to smooth muscle cells (Zhu et al. 1994).

\section{G.4. Toxicity of other tissues:}

Monocrotaline also affects other tissues, the liver after treatment becomes darkly congested, firm on palpation, and has a fine granular surface (Allen et al. 1972). Histopathology of the liver shows centrilobular haemorrhagic necrosis, mid zonal fatty degeneration and formation of cellular aggregates on the luminal surface of central veins. Large parenchymal cells with 2-3 times the diameter of normal cells, become widely scattered in the liver. They have eosinophilic cytoplasm with prominent nucleoli and morphologically correspond with megalocytes (Roth et al. 1981, Allen et al. 1972, Chung and Buhler 1994). Lymph nodes become edematous and congested with sinus cell hyperplasia, and accumulate mononuclear and mast cells in the dilated sinuses. Acute gastric erosions are present and the fluid content 
of the intestine is stained with bile and blood (Turner and Lalich 1965). The mesenteric arteries show a chronic granulomatous arteritis. This change is usually associated with systemic hypertension (Hayashi and Lalich 1967).

The kidneys are discoloured brown and petechial hemorrhages appear in the cortex. Ferrocyanide reaction can disclose deposits of ionizable iron in the proximal convoluted tubules. Glomeruli are swollen and occasionally contained proteinaceous material positive for ferric iron (Hayashi and Lalich 1967). Thrombosis associated with subendothelial hyalinization or even necrosis is noted in glomerular capillaries and afferent arterioles (Roth et al. 1981). The epithelial and mesangeal cells of the tufts undergoes either cytoplasmic vacuolation or karyolysis. Thickening of the interlobular arteries with intimal hyalinization and medial hypertrophy is observed. Hemosiderosis and erythrophagocytosis can also be seen in the renal lymph nodes. Mesenteric arteritis and thickening of the intima and media has been documented in some rats (Hayashi and Lalich 1967).

In conclusion, monocrotaline has been successfully used to induce right heart failure. This is an advantageous model due to the predictability by which right ventricular hypertrophy and failure can be produced, as well as the short period of time needed to obtain results compared with other methods.

In the past, right ventricular failure has been underestimated and, therefore, the biochemical and physiological changes during the development of this pathology have been poorly investigated. The availability of a well characterized model like monocrotaline induced heart failure, affords and excellent opportunity to induce 
specific stages of right heart failure and to study the underlying biochemical changes during the development of right heart failure.

In this review of literature, several deficiencies in our understanding of the pathogenesis of right heart failure have been identified. This animal model of right heart hypertrophy followed by heart failure lends itself to the study of antioxidants as well as oxidative stress changes. The present study attempts to characterize some of these changes during the pathogenesis of right heart failure. 


\section{Material and Methods}

\section{A. Animals and Treatment.}

In preliminary studies, we used different concentrations of monocrotaline in different animal weight groups. This information was used in deciding the dose as well as the post-treatment duration ultimately used in this study. After a one week acclimation period, male Sprague-Dawley rats weighing $110 \pm 8.0 \mathrm{~g}$ received a single intraperitoneal injection ( $50 \mathrm{mg} / \mathrm{Kg}$ body weight) of monocrotaline (Sigma Chemical Co. St Louis, $\mathrm{MO}$ ) in $1 \mathrm{~N} \mathrm{HCl}$ buffered to $\mathrm{pH} 7.0$ with $1 \mathrm{M} \mathrm{NaOH}$. Control animals received the same volume per gram of body weight of a $0.9 \%$ saline solution. Animals were housed one in each cage to allow measurement of individual food and water intake. Their body weight and general appearance was monitored every other day for three weeks after the injections. All of the animal treatment procedures were carried out with approval from, and according to, the regulations of the Canadian Council on Animal Care (CACC) as monitored by the Animal Care Committe of the University of Manitoba

\section{B. Hemodynamic measurements.}

Three weeks after the monocrotaline injection, all animals were assessed hemodynamically. The rats were anaesthetized with an intraperitoneal dose of ketamine $(60 \mathrm{mg} / \mathrm{Kg})$ and xylasine $(10 \mathrm{mg} / \mathrm{Kg})$. When the rats no longer responded to external stimuli, the right jugular vein was exposed and a miniature pressure 
transducer-tipped catheter (model PR249, Millar Instruments Inc. Houston Texas) was inserted through a small incision in the vein and advanced into the right atria and the ventricle. Right ventricular systolic (RVSP) and end diastolic pressure (RVEDP) were recorded using an Axotape software (Axon Instruments, Inc. Foster

City, CA). Following the hemodynamic assessment, animals were killed by decapitation, and the heart, lung and liver were removed. Hearts were immediately washed in $0.033 \mathrm{M} \mathrm{Na} \mathrm{Na}_{2} \mathrm{HPO}_{4} / 0.9 \% \mathrm{KCl}$ buffer for further studies.

\section{Tissue Weights.}

After washing, hearts were blotted dry, and the right ventricle was separated from the left ventricle free wall and the septum. Weights for each heart were recorded and the dissected portions were maintained at $-75^{\circ} \mathrm{C}$ until further analysis. Samples of lung and liver tissue were weighed and chopped into smaller picess for drying in an oven at $55^{\circ} \mathrm{C}$ until a stable weight was obtained. Wet to dry ratios were calculated as a measure of lung and liver congestion.

\section{Antioxidants.}

Both enzymatic and non-enzymatic antioxidants were analyzed as follows:

\section{D.1. Enzymatic Antioxidants.}

\section{D.1.a. Catalase.}

Catalase activity in the right ventricle was determined as described by Clairborne (1985). Tissue was homogenized 1:10 (v/v) in $50 \mathrm{mmol} / \mathrm{L}$ potassium 
phosphate buffer, $\mathrm{pH} 7.4$, the homogenate was then centrifuged at $40,000 \mathrm{Xg}$ for 45 minutes, and the supernatant was stored at $-75^{\circ} \mathrm{C}$ until assayed. Supernatant $(50 \mu \mathrm{l})$ was thawed on ice and added to a $3 \mathrm{ml}$ cuvette that contained $2.95 \mathrm{ml}$ of $19 \mathrm{mmol} / \mathrm{L}$ $\mathrm{H}_{2} \mathrm{O}_{2}$ in $50 \mathrm{mmol} / \mathrm{L}$ potassium phosphate buffer, $\mathrm{pH}$ 7.4. Changes in absorbance at $240 \mathrm{~nm}$ were continuously followed for 5 minutes to determine the disappearance of hydrogen peroxide $\left(\mathrm{H}_{2} \mathrm{O}_{2}\right)$. Catalase activity in samples was extrapolated from a standard curve constructed by assaying commercially prepared Catalase in an identical manner. Activity is expressed as units of catalase per milligram of protein in the supernatant.

\section{D.1.b. Glutathione peroxidase}

Glutathione peroxidase activity in the right ventricle of control and monocrotaline treated rats was determined using a method previously described (Paglia and Valentine 1967). Tissue was homogenized $1: 10(\mathrm{v} / \mathrm{v})$ in $75 \mathrm{mmol} / \mathrm{L}$ phosphate buffer, pH 7.0 and the homogenate was centrifuged at $20,000 \mathrm{Xg}$ for 45 minutes. The supernatant was collected and stored at $-75^{\circ} \mathrm{C}$ until assayed.

Glutathione peroxidase activity was measured in a $3 \mathbf{~ m l}$ cuvette containing 2.0 $\mathrm{ml}$ of $75 \mathrm{mmol} / \mathrm{L}$ phosphate buffer, $\mathrm{pH}$ 7.0. The following solutions were then added, $50 \mu \mathrm{l}$ of $60 \mathrm{mmol} / \mathrm{L}$ glutathione, $100 \mu \mathrm{l}$ of glutathione reductase solution $(30 \mathrm{U} / \mathrm{ml})$, $50 \mu \mathrm{l}$ of $0.12 \mathrm{~mol} / \mathrm{L}$ sodium azide, $100 \mu \mathrm{l}$ of $15 \mathrm{mmol} / \mathrm{L} \mathrm{Na} \mathrm{NDT}_{2} \mathrm{E}, 100 \mu \mathrm{l}$ of 3.0 $\mathrm{mmol} / \mathrm{L}$ reduced nicotinamide adenine dinucleotide phosphate (NADPH), and 100 $\mu l$ of the supernatant that had been thawed on ice. The reaction was started by the 
addition of $100 \mu \mathrm{l}$ of $7.5 \mathrm{mmol} / \mathrm{L} \mathrm{H}_{2} \mathrm{O}_{2}$. The conversion of NADPH to nicotinamide adenine dinucleotide phosphate (NADP) was monitored by the change of absorbance at $340 \mathrm{~nm}$ for 5 minutes. GSHPx activity was expressed as nanomoles of NADPH oxidized to NADP per minute per milligram of protein, with a molar extinction coefficient for NADPH at $340 \mathrm{~nm}$ of $6.22 \times 10^{6}$.

\section{D.1.c. Superoxide Dismutase.}

Superoxide dismutase activity in the right ventricle was determined by the method described earlier (Marklund 1985). Tissue was homogenized in 1:10 (v/v) of $75 \mathrm{mmol} / \mathrm{L}$ phosphate buffer, $\mathrm{pH} 7.0$ and the homogenate was centrifuged at 20,000 $\mathrm{X} g$ for 45 minutes. The supernatant was collected and stored at $-75^{\circ} \mathrm{C}$ until assayed.

SOD activity was measured by following the inhibition of pyrogallol autooxidation. Pyrogallol $(24 \mathrm{mmol} / \mathrm{L})$ was prepared in $10 \mathrm{mmol} / \mathrm{L} \mathrm{HCl}$ and kept at $4^{\circ} \mathrm{C}$ before use. Catalase ( $30 \mu \mathrm{mol} / \mathrm{L}$ stock solution) was dissolved in an alkaline buffer (pH 9.0). Aliquots of the supernatant (150 $\mu \mathrm{g}$ of protein) were added to Tris- $\mathrm{HCl}$ buffer containing $25 \mu \mathrm{l}$ of pyrogallol and $10 \mu \mathrm{l}$ of catalase. The final volume of $3 \mathrm{ml}$ was made up with the same buffer. Changes in absorbance at $420 \mathrm{~nm}$ were recorded for 5 minutes to follow pyrogallol autoxidation. SOD activity was determined from a standard curve of percent inhibition of pyrogallol auto-oxidation with commercially available SOD (Sigma Chem Co, St. Louis MO). Data are expressed as total SOD units per milligram of protein in the supernatant. 


\section{D.2. Non-enzymatic Antioxidants.}

Only $\alpha$-tocopherol and retinol were analized to assess the non-enzymatic antioxidants.

\section{D.2.a. Extraction Procedure.}

Tocopherol and retinol were determined using an adaptation of the HPLC method described earlier (Palace and Brown 1994). Briefly, $100 \mathrm{mg}$ of tissue were homogenized in $4 \mathrm{ml}$ of double distilled water. The homgenate was transferred to a $15 \mathrm{ml}$ screw cap test tube and $2 \mathrm{ml}$ of ethanol containing tocopherol acetate $(72.5$ $\mu \mathrm{g} / \mathrm{ml})$ as an internal recovery standard were added to each sample. After thorough mixing, a mixture of $2 \mathrm{ml}$ of ethyl acetate: hexane $(3: 2 \mathrm{v} / \mathrm{v})$ was added to each tube and the tubes were again thoroughly vortexed and allowed to stand on ice for 10 minutes and shielded from light. The ethyl acetate:hexane layer was separated from the aqueous layer by centrifugation at $2500 \mathrm{Xg}$ for 3 minutes. One $\mathrm{ml}$ of the top ethyl acetate:hexane layer was retrieved and dried completely under vacuum in a rotary evaporator. Once dry (approximately 20 minutes), the oily residue was reconstituted in $70 \mu \mathrm{L}$ of mobile phase and this solution was directly injected into the HPLC system. Chromatogram peaks for each sample were corrected for extraction efficiency using the tocopherol acetate peak recovered in the sample against the peak obtained by injecting tocopherol acetate stock solution directly. Tocopherol and retinol concentrations in each sample were extrapolated from standard curves (tocopherol $=400$ to $1600 \mathrm{ng}$, and retinol $=10$ to $40 \mathrm{ng}$ in the $20 \mu \mathrm{L}$ HPLC 
injection loop volume) constructed with commercially prepared compounds (Sigma Chem. Co., St. Louis, MO).

\section{D.2.b. HPLC System.}

An isocratic system using 70:20:10 (v/v|v) acetonitrile : dichloromethane : methanol as the mobile phase was employed. The mobile phase was delivered at 1 ml per minute by a Beckman Model 116 pump through an Adsorbosphere HS C18 (250 mm X $4.6 \mathrm{~mm}$ I.D., $5 \mu \mathrm{m}$ pore size) analytical column preceeded by a $15 \mathrm{~mm}$ guard column with the same packing material. Ultraviolet detection of peaks by a Beckman model 166 programmable detector was accomplished by monitoring at 325 nm until 7 minutes for retinol and then switching to $292 \mathrm{~nm}$ for detection of tocopherol. Total run time was $\mathbf{3 0}$ minutes, with typical retention times for retinol and tocopherol of 4.5 and 10.9 minutes, respectively.

\section{E. Lipid hydroperoxides.}

For the determination of lipid hydroperoxides, myocardial tissue $(0.3 \mathrm{~g})$ was homogenized in 10 volumes of double distilled water and extracted with $2 \mathrm{ml}$ of chloroform/methanol $(2: 1 \mathrm{v} / \mathrm{v}), 1.5 \mathrm{ml}$ of this extract was completely dried under vacuum in a rotary evaporator and reconstituted in $70 \mu \mathrm{l}$ of isopropyl alcohol. $30 \mu \mathrm{l}$ of this solution was then assayed using a commercial kit specific for lipid hydroperoxides (Kamiya Biomed Co, Seattle, WA). This kit uses a derivative of methylene blue (10-N-methylcarbamoyl-3,7 dimethylamino-10H phenothiazine 
MCDP) which is specifically cleaved by lipid hydroperoxides to yield methylene blue dye, which can be quantified supectrophotometrically at $675 \mathrm{~nm}$.

G. Statistical Analysis.

Data from the control and monocrotaline groups were compared using Students t-test. Where data were not normally distributed or had a nonhomogeneous variance, means were compared using the Mann-Whitney rank sum test. Significance for both types of data analyses was accepted at the $p<0.05$ level. 


\section{RESULTS}

\section{A. Body weight and general appearance.}

After the administration of monocrotaline or saline injection in sham controls, body weight, food and water intake were recorded every other day. Four days after the administration of monocrotaline the rats showed a general lack of appetite. Water consumption by these animals was also decreased. This condition of lower food and water intake was seen throughout the study in monocrotaline injected rats.

Although animals in both control and monocrotaline groups showed weight gain, the gain in monocrotaline treated rats was significantly lower than the gain seen in control rats (Fig. 3). The differences became statistically significant $(p<0.05)$ four days after injection. The weight difference continued to increase throughout the post treatment duration and at the end of 3 weeks, weight gain in the monocrotaline treated rats was about $20 \%$ less than control rats.

Two weeks after the treatment, monocrotaline treated rats began exhibiting other signs of cardiac duress. In addition to the marked decrease in body weight and the lack of appetite, there were signs of fatigue and cyanosis of limbs and ear lobes. At three weeks after the treatment, monocrotaline treated rats also showed signs of pulmonary impairment, evidenced by shortness of breath.

\section{B. Assessment of hypertrophy.}

In order to assess the extent of heart hypertrophy developed by the rats 
$\rightarrow$ Control

$\square$ Monocrotaline

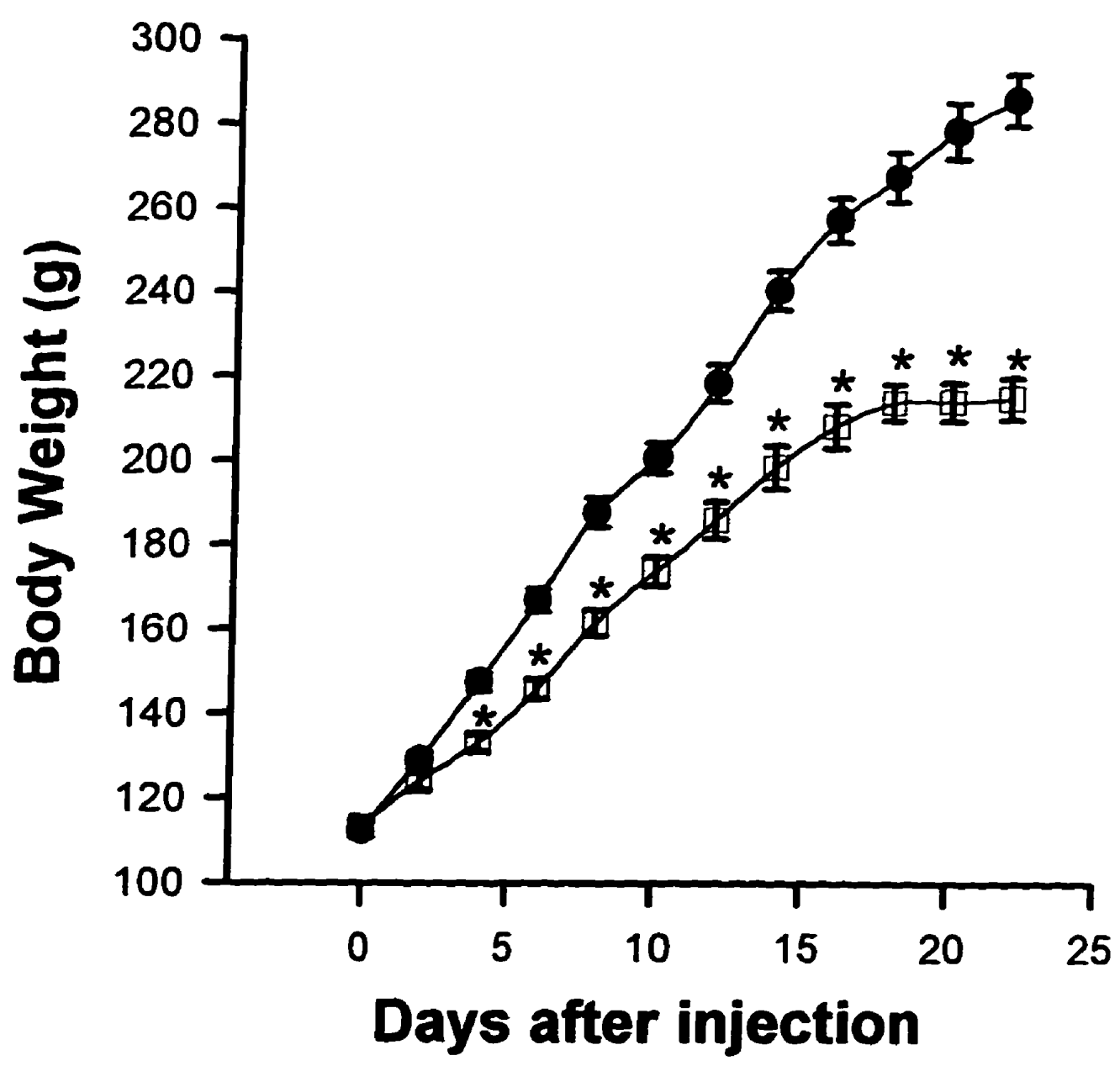

Fig. 3. Body weight gain in rats after monocrotaline $(n=25)$ or vehicle $(n=15)$ injection. *) Significantly different from the control $(p<0.05)$ 
injected with monocrotaline, the right and left ventricular weights were recorded along with an assessment of ventricular to body weight ratio (Table 1). Both right ventricular weight and ventricular to body weight ratio increased significantly in the monocrotaline rats three weeks after monocrotaline treatment. Left ventricular weight in the monocrotaline group decreased compared to the control rats. When this data was normalized for body weight, there was also an increase in left ventricular to body weight ratio (Table 1).

\section{Lung and Liver wet to dry weight ratio.}

In order to estimate the extent of heart failure in the monocrotaline treated rats, wet to dry weight ratios of lung and liver were determined (Table 2). Compared to control values, neither the lung nor the liver showed any change in the wet to dry weight ratio.

\section{Hemodynamic changes.}

After catheterization, a few minutes of stabilization were allowed for the recording of heart rate and right ventricular pressures (Table 3). In control rats right ventricular systolic pressure (RVSP) was $30.6 \pm 2.6 \mathrm{mmHg}$, whereas the value in the monocrotaline treated rats was $50 \pm 5.1 \mathrm{mmHg}(\mathrm{p}<0.05)$. The same pattern was found when analyzing the right ventricular end diastolic pressure (RVEDP), where monocrotaline treated rats showed a marked increase in RVEDP $(8.9 \pm 2.0$ $\mathrm{mmHg})$ compared to control rats $(2.1 \pm 1.5 \mathrm{mmHg})$. There was no significant 


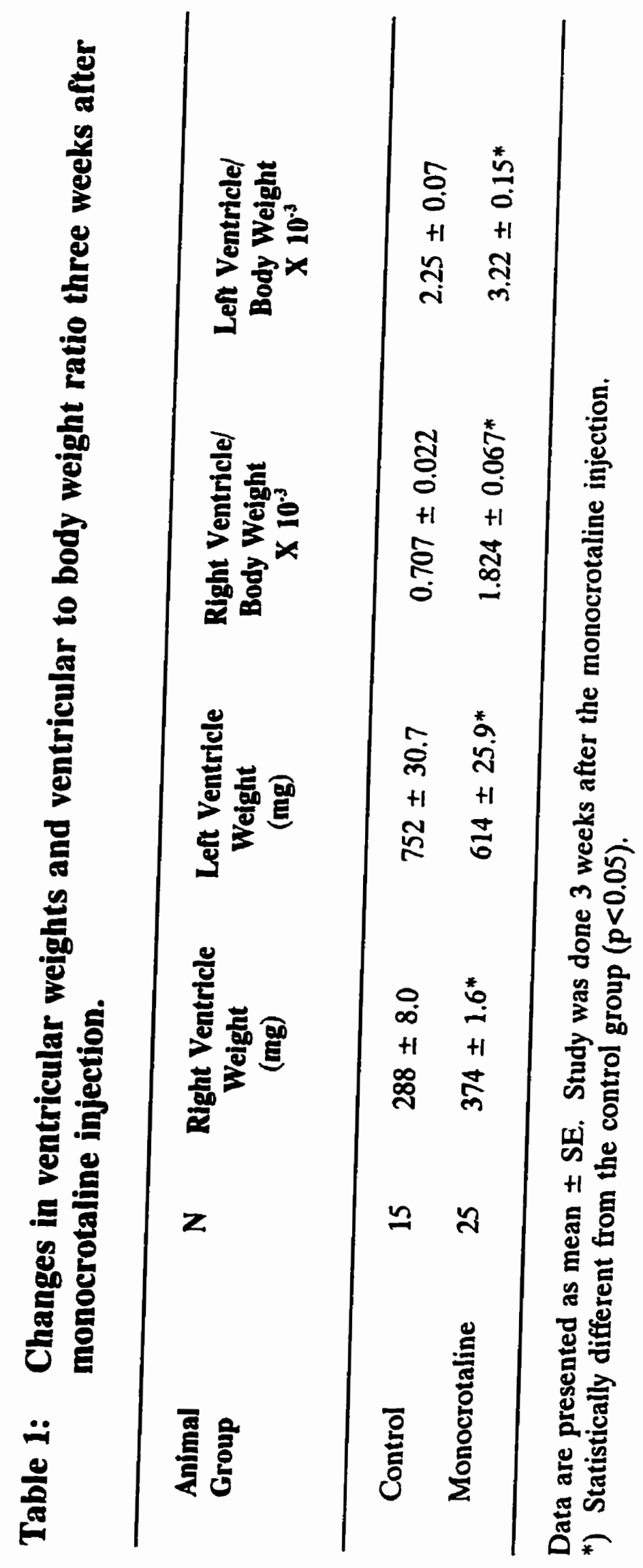


Table 2: Lung and liver wet to dry weight ratios, three weeks after monocrotaline injection.

\begin{tabular}{lccc}
\hline $\begin{array}{c}\text { Animal } \\
\text { Group }\end{array}$ & N & Lung & Liver \\
\hline Control & 12 & $4.66 \pm 0.11$ & $3.14 \pm 0.08$ \\
Monocrotaline & 14 & $4.04 \pm 0.29$ & $3.22 \pm 0.14$ \\
\hline
\end{tabular}

Data are presented as mean $\pm \mathrm{SE}$. 
Table 3: Heart rate and right ventricular pressure changes in rats three weeks after the monocrotaline injection.

\begin{tabular}{lllll}
$\begin{array}{c}\text { Animal } \\
\text { Group }\end{array}$ & N & $\begin{array}{c}\text { Heart Rate } \\
\text { (beats/min) }\end{array}$ & \multicolumn{2}{c}{$\begin{array}{c}\text { Right VentricularPressure } \\
\text { Systolic }\end{array}$} \\
\hline Control & 23 & $322 \pm 10$ & $30.6 \pm 2.6$ & $2.1 \pm 1.5$ \\
Monocrotaline & 10 & $295 \pm 8$ & $50.0 \pm 5.1^{*}$ & $8.9 \pm 2.0^{*}$ \\
\hline
\end{tabular}

Data are presented as mean \pm SE. *) Significantly different from the control group $(p<0.05)$. Student's t-test followed by Mann Whitney. 
difference between the monocrotaline $(295 \pm 8 \mathrm{bpm})$ and control $(322 \pm 10 \mathrm{bpm})$ groups with respect to their heart rate.

\section{E. Antioxidants.}

In order to establish the antioxidant status of the myocardial tissue, activities of both enzymatic and non-enzymatic antioxidants were analyzed in the right ventricle.

\section{E.I Enzymatic Antioxidants:}

\section{E.1.a. Catalase.}

The activity of catalase, an antioxidant enzyme that catalyzes the conversion of hydrogen peroxide $\left(\mathrm{H}_{2} \mathrm{O}_{2}\right)$ to oxygen $\left(\mathrm{O}_{2}\right)$ plus water $\left(\mathrm{H}_{2} \mathrm{O}\right)$ in the right ventricle of controls was $28.85 \pm 2.14 \mathrm{nmol} / \mathrm{mg}$ protein. Compared to control rats, the activity in the right ventricle of monocrotaline treated rats was not significantly different (Fig 4).

\section{E.1.b Glutathione peraxidase.}

Glutathione peroxidase also catalyzes the conversion of $\mathrm{H}_{2} \mathrm{O}_{2}$ to $\mathrm{H}_{2} \mathrm{O}$ plus $\mathrm{O}_{2}$ but the difference is that GSHPx can also catalize organic peroxides. The activity of this enzyme in right ventricle of control rats was $31.94 \pm 3.88 \mathrm{nmol} / \mathrm{mg}$ protein and it was also not significantly different form the activity $35.19 \pm 3.07 \mathrm{nmol} / \mathrm{mg}$ protein measured in the monocrotaline group (Fig 5). 
$\square$ Control

Monocrotaline

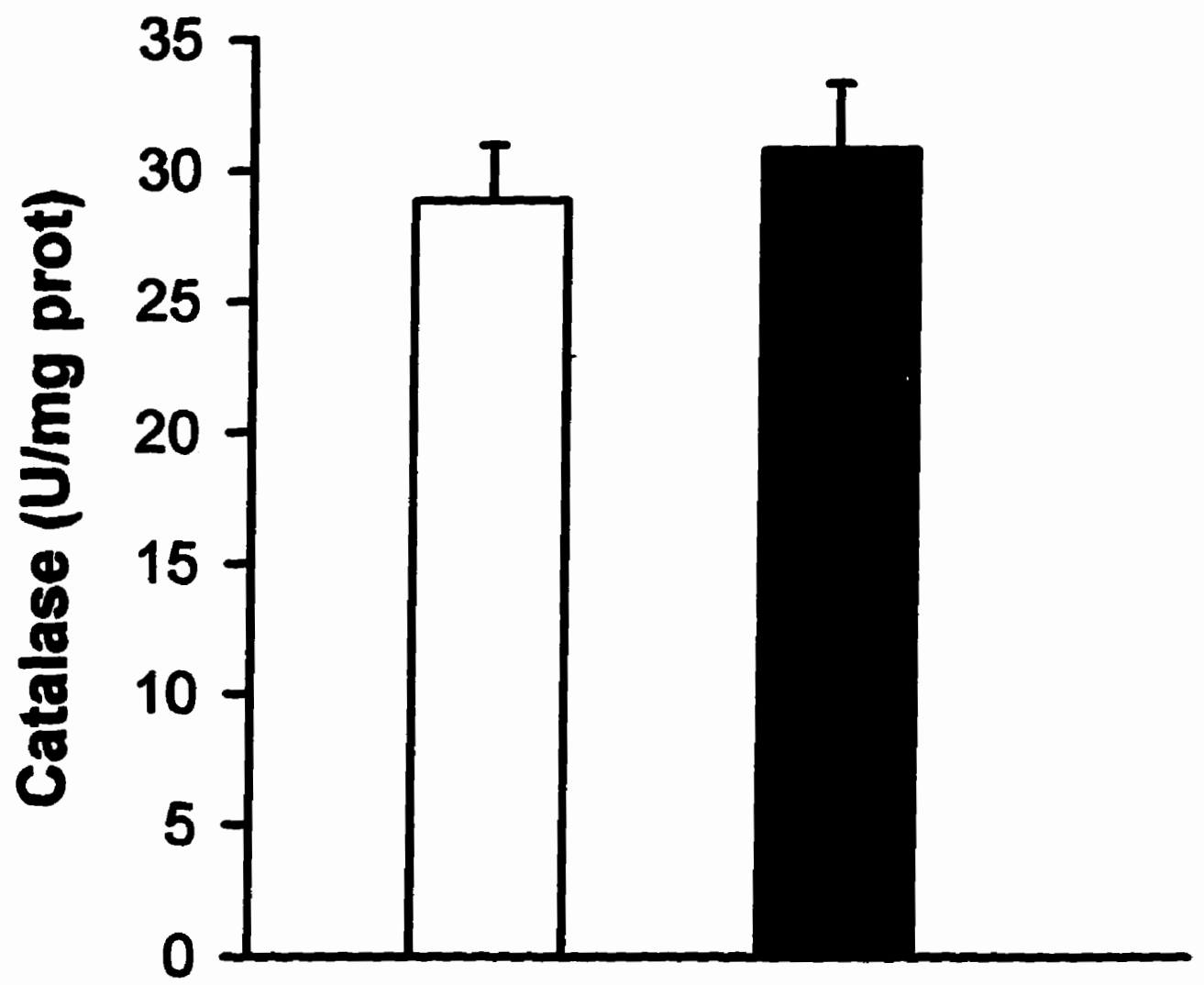

Fig. 4. Catalase activity in the right ventricle from control $(n=10)$ and monocrotaline $(n=20)$ treated rats, 3 wks. after injection. 


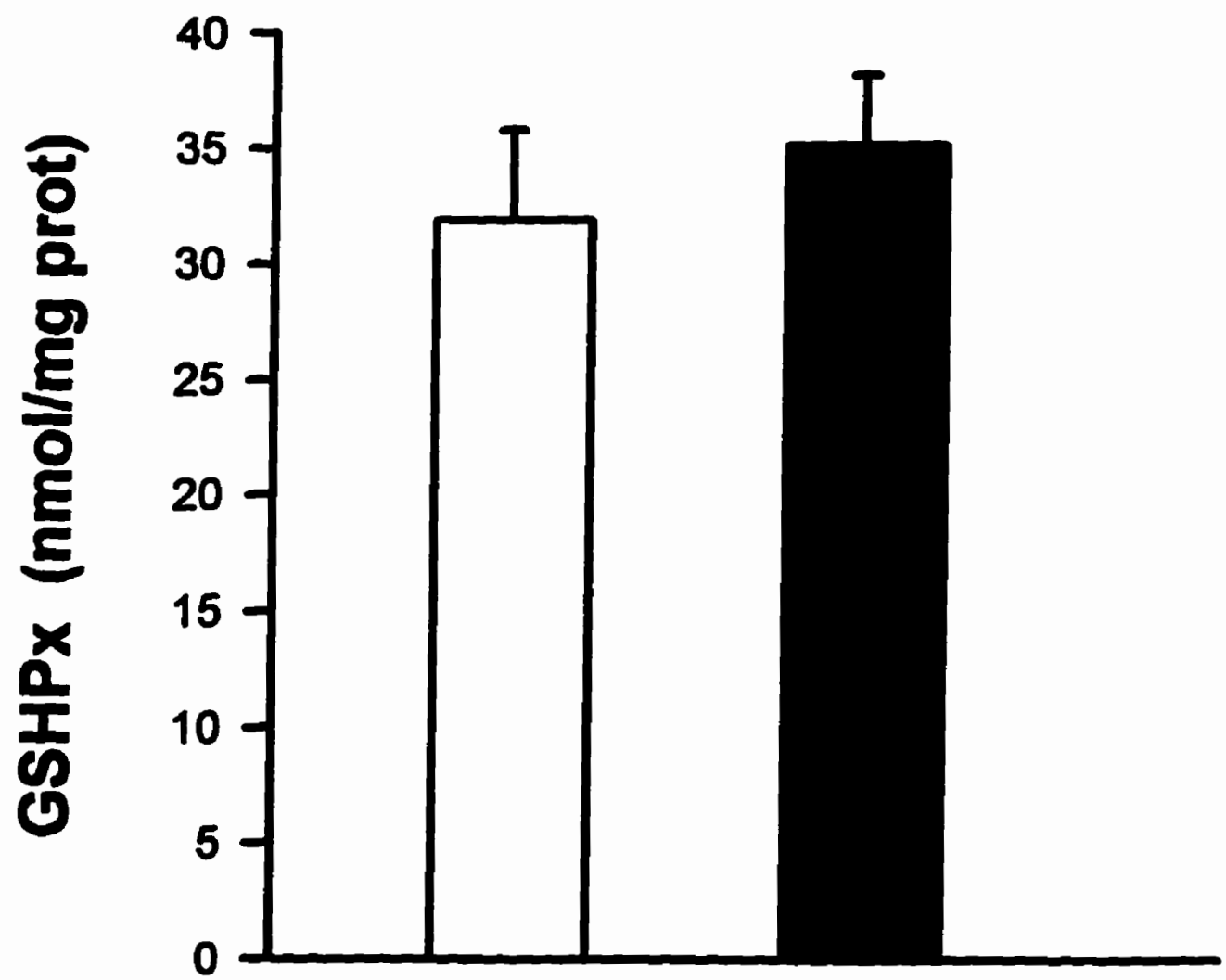

Fig. 5. Glutathione peroxidase (GSHPx) activity in the right ventricle from control $(n=10)$ and monocrotaline $(n=20)$ treated rats, 3 weeks after injection 


\section{E.1.c Superoxide dismutase.}

Superoxide dismutase catalyzes the conversion of superoxide $\left(\mathrm{O}_{2}^{-}\right)$, which is normally generated by the electron transport chain, to $\mathrm{H}_{2} \mathrm{O}_{2}$. The activity of superoxide dismutase, in the right ventricle of monocrotaline treated rats was 45.59 $\pm 7.77 \mathrm{U} / \mathrm{mg}$ protein and it was not significantly different compared to the activity $39.77 \pm 4.93 \mathrm{U} / \mathrm{mg}$ protein found in the right ventricle of the control rats (Fig.6).

\section{E.2 Non-enzymatic Antioxidants.}

\section{E.2.a. Tocopherol.}

Tocopherol content was analyzed in both groups and these data are shown in figure 7. The concentration of tocopherol in the right ventricle of rats from the monocrotaline treated group ( $31.51 \pm 4.09 \mu \mathrm{g} / \mathrm{g}$ wet weight) was significantly lower than the control group $(47.1 \pm 2.98 \mu \mathrm{g} / \mathrm{g}$ wet weight).

\section{E.2.b. Retinol.}

Retinol, the free alcohol form of vitamin $\mathbf{A}$ has also been recently proposed as an antioxidant. It was analyzed in control as well as monocrotaline group and these data are shown in figure 8. Rats injected with monocrotaline had retinol concentrations in the right ventricle $(0.3786 \pm 0.027 \mu \mathrm{g} / \mathrm{g}$ wet weight $)$ similar to those of the control rats $(0.3986 \pm 0.032 \mu \mathrm{g} / \mathrm{g}$ wet weight $)$. 




Monocrotaline



Fig. 6. Superoxide Dismutase activity in the right ventricle from control $(n=10)$ and monocrotaline $(n=20)$ treated rats, 3 wks. after injection. 


\section{Control}

Monocrotaline



Fig. 7. Tocopherol concentration in right ventricle of control $(n=10)$ and monocrotaline $(n=15)$ treated rats, 3 weeks after injection.

*) Significantly different from the control ( $p<0.05)$ (Student's t-test). 


\section{$\square$ Control Monocrotaline}

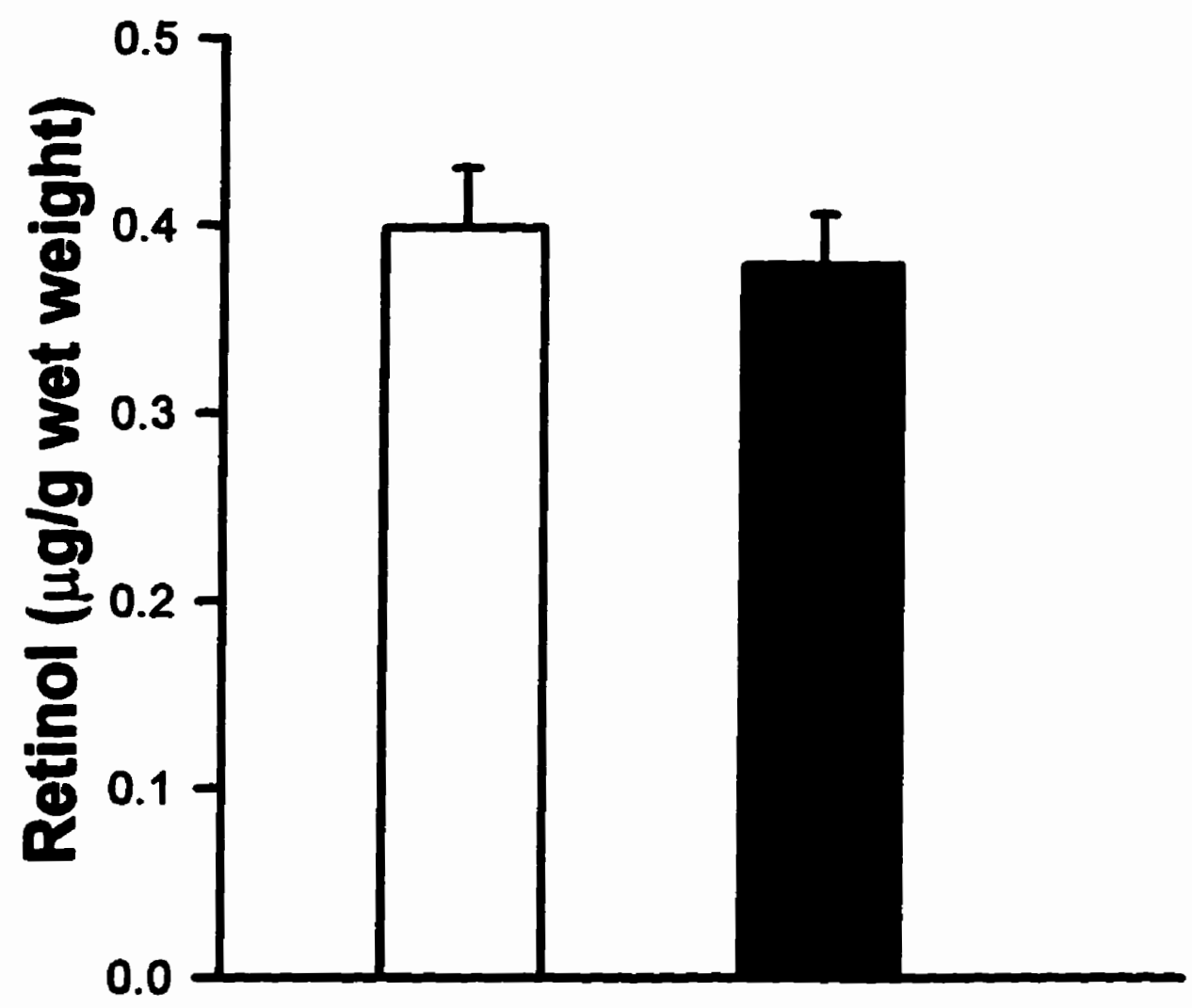

Fig. 8. Retinol concentration in right ventricle of control $(n=6)$ and monocrotaline $(n=6)$ treated rats, 3 wks. after injection. 


\section{F. Lipid hydroperoxides.}

For an assessment of the overall oxidative stress lipid hydroperoxides were analyzed and these data are shown in figure 9. Lipid hydroperoxides levels were significantly different $(p<0.05)$ in the right ventricle of monocrotaline treated rats $(25.61 \pm 9.09 \mathrm{nmol} / \mathrm{g})$ compared to the control right ventricle $(9.08 \pm 3.25 \mathrm{nmol} / \mathrm{g})$. 
$\square$ Control

Monocrotaline

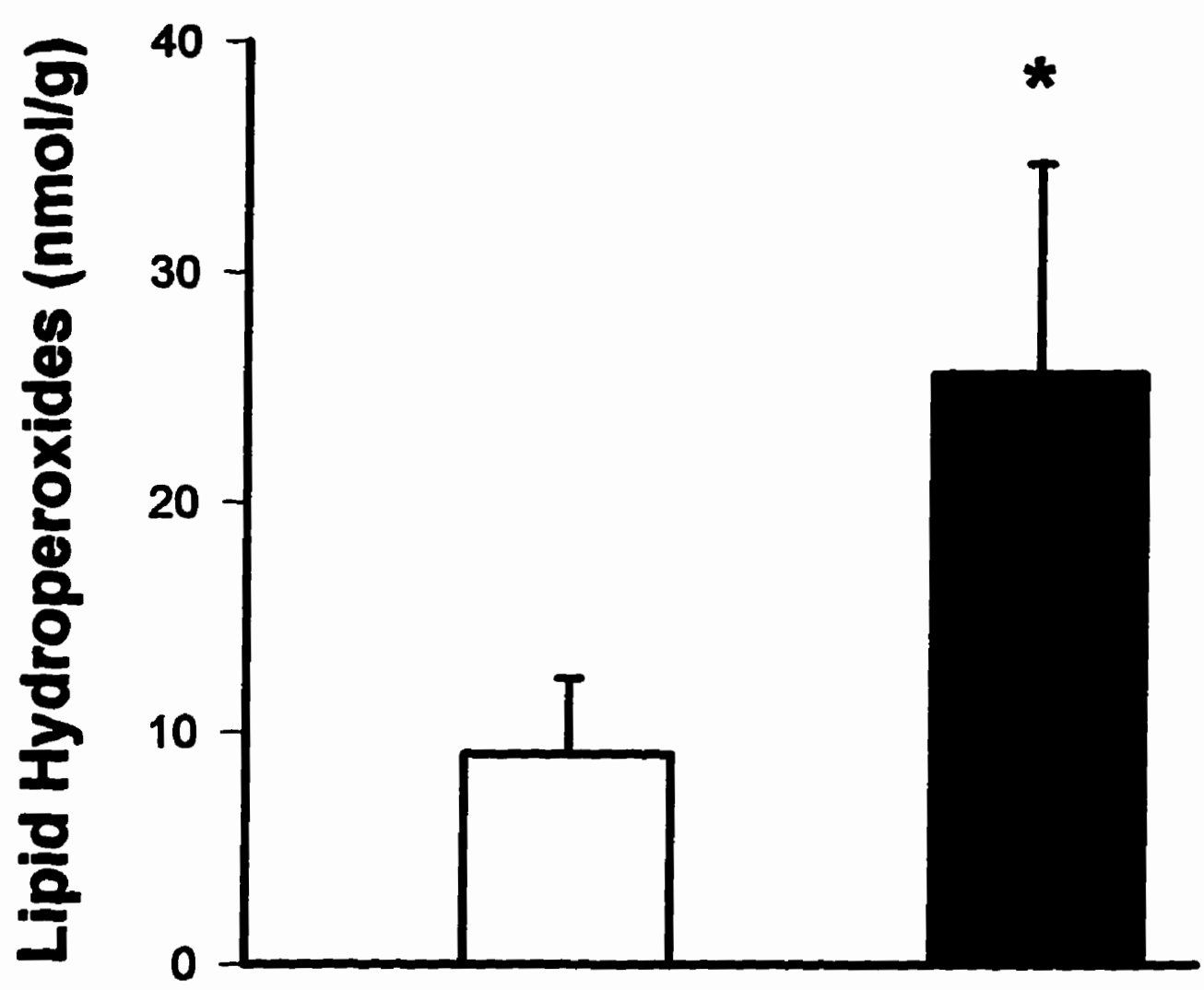

Fig. 9. Concentration of lipid hydroperoxides in right ventricles of control $(n=4)$ and monocrotaline $(n=7)$ treated rats, 3 wks. after injection.

*) Significantly different from the control (p<0.05). 


\section{DISCUSSION}

During the last few years, our realization of the extensive problem of RHF has placed a premium on establishing a better understanding of the mechanisms underlying this condition. It is now known that plasma catecholamine levels and ANP are increased during RHF (Angoletti et al. 1990, Ceconi et al. 1989, Comini et al. 1995). There are also losses in important enzymes (Ishikawa et al. 1995), a shift from V1 to V3 myosin isoenzyme, and a change in collagen isoforms during RHF (Morioka et al. 1992, Ishikawa et al. 1995). All of these alterations are signatures of changes in RHF. Considering the high incidence of cardiovascular complications due to RHF, we need to characterize subcellular changes as well as their significance in the pathogenesis of RHF.

In order to examine the role of oxidative stress in RHF, rats were injected with a single dose of the pyrrolizidine alkaloid, monocrotaline. The treatment increase the workload imposed on the right heart. This has the advantage that it does not require surgery. By conducting some pilot experiments, we were able to establish the dose of monocrotaline which resulted in stages of hypertrophy, compensated heart failure followed by overt heart failure with in $5-7$ weeks. This spectrum was affected by both age of the animal and dose of the drug.

Clinical right heart failure is usually produced by a chronic increase in pulmonary artery pressure or by an inadequacy of the tricuspid or pulmonary valves. Monocrotaline induces RHF by its effect on the pulmonary circuit without directly 
affecting the heart. After monocrotaline injection, the stage of heart hypertrophy is seen in the first two weeks, followed by phases of compensatory heart failure at 3-4 weeks and overt heart failure at 5-7 weeks. It should be noted that this classification is based on the right ventricle to body weight ratio, hemodynamics and clinical observations. In the present study, animals were in compensated failure as explained later.

Animals in the monocrotaline group grew less compared to the control group, as has also been reported by others (Ceconi et al, 1989 and Comini et al, 1995). Differences in growth became apparent and this difference widened with an increase in post-treatment duration. This effect is probably due to gastrointestinal system disturbances as well as direct effects of monocrotaline on the liver, where the drug produces veno-occlusive disease which, may have adverse effects on the growth. After monocrotaline is bioactivated in the liver, its derivative travels to the lungs where it induces pulmonary damage causing pulmonary hypertension (Huxtable 1990, Pan et al. 1993) with in a short period of time. At this point the rats showed signs of laboured breathing and they appeared listless and pale. These animals at three weeks had elevated RVSP and RVEDP. These results suggest a compensatory phase during which cardiac output is maintained by pumping blood with an elevated pressure through the narrowed pulmonary circulation. Therefore, three weeks after monocrotaline injection animals were in compensated heart failure, and were hemodynamically stable.

Detailed examination of the hearts of these rats, revealed that the right 
ventricle was hypertrophied, and weighed about 1.5 times more than the right ventricle of control rats. This difference when analyzed in relation to the body weight was increased to $157 \%$. In the monocrotaline group, left ventricular weight. however, was significantly less as compared to the control group. Because of the reduced gain in body weight in the monocrotaline group, the left ventricular to body weight ratio was also significantly increased in the monocrotaline group. Thus using the criteria of ventricle to body weight ratio, both ventricles showed hypetrophy.

Increase in the RVEDP suggested that the ventricle functioning on the FrankStraling curve had shifted to the right and suggested ventricular failure. Increase in EDP is also considered as a hallmark of heart failure (Hill and Singal 1996, Khaper and Singal 1997). Since the ventricle was able to develop higher than normal systolic pressure, it is considered to be compensated heart failure.

In left ventricular failure, once heart failure is established there is edema of the lungs followed by edema of the liver manifested by an increase in wet to dry weight ratio (Randhawa and Singal 1992, Khaper and Singal 1997). The same general phenomenon appears in right ventricular failure $\mathrm{Ng}$ et al 1995 , Comini et al 1996), except that liver congestion appears before lung congestion. In this study, neither liver nor lung wet to dry weight ratios were different from the controls. This could be explained by the increase in both RVSP and RVEDP, that is providing enough blood to satisfy the metabolical needs of both tissues at this particular stage. This further supports the conclusion that rats at this particular stage are still in the compensated stage of heart failure, where the hypertrophied heart is still able to 
pump enough blood to satisfy the needs of the different organs.

It has previously been reported that the left ventricle of the rats injected with monocrotaline is not affected by changes taking place in the lungs or in the right ventricle (Angoletti et al 1990). In contrast, in the present study it was observed that the left ventricular weight of the monocrotaline treated rats was significantly lower than in the control. When the ventricular weight was corrected for body weight. there was an increase in the ratio of left ventricle to body weight. The difference from Angoletti's study may be due to the fact that rats receiving the monocrotaline injection in this study were juveniles and still growing. When pulmonary hypertension occurs in these animals, there may be a decrease in the amount of blood going to the left ventricle and perhaps to the body.

There are at least three phases in the development of heart failure, each one characterized by specific physiological and biochemical changes of the myocardial cells. However, there is still a lack of information regarding the neurohormonal and cardiac changes that occur during the compensated phase of right heart failure. Studies of left ventricular hypertrophy bave demonstrated a significant increase in antioxidant enzyme activity and reduction in lipid peroxidation, which suggest that this phase has better protection against oxidative stress (Singal and Kirshenbaum 1990, Dhalla and Singal 1994). In contrast, during left ventricular heart failure there is a significant increase in oxidative stress and a decrease in antioxidant enzyme activities. In contrast to the results from left ventricular hypertrophy stage studies, results from the present study show that during the compensated right ventricular 
failure, the activity of the antioxidant enzymes was not different from the activity of the control rats. It should be emphasized that an increase in antioxidants and decrease in oxidative stress reported earlier corresponded to the hypertrophy stage without any failure (Dhalla and Singal 1994). It is possible that in the present study, the animals had gone past that stage and the antioxidant enzymes changes were on the decline and were now near control levels.

Experimental evidence in support of the role of oxidative stress in the pathogenesis of heart failure in animal models is overwhelming (Hill and Singal 1996, Siveski-Iliskovic et al. 1994, Khaper and Singal 1997). A limited data set on patients in some clinical studies corroborates this notion (Hoffman and Garewal 1995, Singh et al. 1996, Weitz et al. 1991, McMurray et al. 1990, Stephens et al. 1996). Thus left ventricular failure corresponding to a decrease in the antioxidant status and an increase in oxidative stress has been documented in a number of studies (SiveskiIliskovic et al. 1994, Hill and Singal 1996). The present study shows for the first time that compensated failure in the right heart also corresponds to an increase in oxidative stress.

Previous studies of the non-enzymatic antioxidants in left ventricular failure, have shown that depleted concentrations of vitamin $E$ and vitamin $A$ are often correlated with increased lipid peroxidation (Lemoyne et al. 1987, Hill and Singal 1996). In this study of compensated beart failure, the non-enzymatic antioxidant retinol did not differ from the control group, but tocopherol significantly declined. The decline in tocopherol concentration indicates that oxidative stress is present 
during compensated right ventricular failure. The fact that only tocopherol concentrations were affected, may indicate sensitivity of this antioxidant. Vitamin $E$ is a potent antioxidant and its presence in biological membranes represents the major defense system against membrane lipid peroxidation (Hill and Singal 1996). The significant increase in the right ventricular lipid hydroperoxides concentrations and the decline in vitamin $E$ content of the right ventricle of the monocrotaline group shows that oxidative stress is present even when the right ventricle is hemodynamically compensated. This occurs even when none of the other normally affected tissues (lungs and liver) are not compromised.

Heart failure stage, experimental as well as clinical, has been shown to be associated with a decrease in myocardial antioxidant enzymes (Siveski-Iliskovic et al. 1994, Khaper and Singal 1997), non enzymatic antioxidants (Hill and Singal 1996) and increased oxidative stress. In the present study only 2 out of these 3 defects were noted. This may have to do with the fact that the animals were in compensated heart failure stage, a step before the establisment of the overt failure stage. In order to resolve this issue, we need to examine the time course of these changes in monocrotaline treated animals.

In conclusion, the present study defines early changes in antioxidants in compensated heart failue. This study also emphasize the need to understand the role of oxidative stress during right heart failure. In particular, the decompensated phase of right ventricular failure, where further increases in lipid hydroperoxides production and antioxidant depletion are likely to take place, requires further study. 


\section{REFERENCES}

Allen DG, Orchard CH. Intracellular calcium concentration during hypoxia and metabolic inhibition in mammalian ventricular muscle. J Physiol. 1983; 339:107-122.

Allen JR, Chesney CF, Frazee WJ. Modifications of pyrrolizidine alkaloids intoxication resulting from altered hepatic microsomal enzymes. Toxicol Appl Pharmacol. 1972; 23:470-479.

Altiere RJ, Olson JW, Gillespie MN. Altered pulmonary vascular smooth muscle responsiveness in monocrotaline-induced pulmonary hypertension. J Pharmacol Exp Ther. 1986; 236:390-395.

Anfossi G, Trovati M. Role of catecholamines in platelet function: pathophysiological and clinical significance. Eur J Clin Invest. 1996; 26:353-370.

Angoletti G, Cornacchiari A, Panzali AF, Ghielmi S, De Giuli F, Ferrari R. Effect of congestive heart failure on rate of atrial natriuretic factor release in response to stretch and isoprenaline. Cardiovasc Res. 1990; 24:938-945.

Arias-Stella J, Saldana $\mathrm{M}$. The muscular pulmonary arteries in people native to high altitude. Med Thorac. 1962; 19:484-493.

Bassand JP. Left ventricular remodelling after acute myocardial infarction - solved and unsolved issues. Eur Heart J. 1995; 16:58-63.

Belch JJF, Bridges AB, Scott N, Chopra M. Oxygen free radicals and congestive heart failure. $\mathrm{Br}$ Hear J. 1991; 65:245-248.

Bell D, Sackson M, Nicoll JJ, Miller A, Dawes J, Muir AT. Inflammatory response, neutrophil activation and free radical production after acute myocardial infarction: effect of thrombolytic treatment. Br Heart J. 1990; 63:82-87. 
Bernier M, Hearse DJ, Manning AS. Reperfusion induced arrhythmias and oxygen derived free radicals. Circ Res. 1996; 58:331-340.

Bessman SP, Yang WCT, Geiger PJ, Erickson-Vütanen S. Intimate coupling of creatine phosphokinase and myofibrillar adenosine triphosphatase. Biochem Biophys Acta Commun. 1990; 96:1414-1420.

Boor PJ, Gotlieb AI, Joseph EC, Kerns WD, Roth RA, Tomaszewski KE. Chemicalinduced vasculature injury. Toxicol Appl Pharmacol. 1995; 132:177-195.

Braunwald E, Grossman W. Clinical aspects of heart failure. In Heart disease: a textbook of cardiovascular medicine. Ed. Braunwald E. Philadelphia, PA. W.B. Saunders company. 1992. 444-463.

Bruner LH, Hilliker KS, Roth RA. Pulmonary hypertension and ECG changes from monocrotaline pyrrole in the rat. Am J Physiol. 1983; 245:H300-H306.

Burton GW, Traber MG. Vitamin E: antioxidant activity, biokinetics and bioavailability. Ann Rev Nutr. 1990; 10:357-382.

Carroll SM, Nimmo LE, Knoepfler PS, White FC, Bloor CM. Gene expression in a swine model of right ventricular hypertrophy: intracellular adhesion molecule, vascular endothelial growth factor and plasminogen activators are upregulated during pressure overload. J Mol Cell Cardiol. 1995; 27:1427-1441.

Ceconi C, Condorelli E, Quinzanini M, Rodella A, Ferrari R, Harris P. Noradrenaline, atrial natriuretic peptide, bombesin and neurotensin in myocardium and blood of rats in congestive heart failure. Cardiovasc Res. 1989; 23:674-682.

Chance $\mathbf{B}$, Sies $\mathbf{H}$, Boveris A. Hydroperoxide metabolism in mammalian organs. Physiol Rev. 1979; 59:527-605.

Chesney CF, Allen JR. Pulmonary hypertension, Cor Pulmonale and endocardial fibroelastosis in monocrotaline intoxicated non-human primates. Comp Pathol Bull. 1973; 70:489-492. 
Chung WG, Buhler DR. The effect of spironolactone treatment on the cytochrome P450-mediated metabolism of the pyrrolizidine alkaloid senecionine by hepatic microsomes from rats and guinea pigs. Toxicol Appl Pharmacol. 1994; 127:314-319.

Clairborne A. Catalase Activity. Handbook of methods for oxygen radical research. Edited by RA Greenwald. Boca Raton, FL, CRC Press, 1985, pp 283-284.

Comini L, Agnoletti G, Panzali A, Mantero G, Pasini E, Gaia G, Albertini A, Ferrari R. Activation of atrial natriuretic peptide synthesis during congestive heart failure in rats treated with monocrotaline. Am J Physiol. 1995; 268:H391-H398.

Culvenor CCJ, Dan AT, Dick AT. Alkylation as the cell mechanism by which the hepatotoxic pyrrolizidine alkaloids act on cell nuclei. Nature. 1962; 195;570-573.

Dhalla AK, Singal PK. Antioxidant changes in hypertophied and failing guinea pig hearts. Am J Physiol. 1994; 266:H1280-H1285.

Dhalla NS, Lee SL, Shah KR, Elimban V, Suzuki S, Jasmin G. Behaviour of subcellular organielles during the development of congestive heart failure in cardiomyopathic hamsters. In The cardiomyopathic heart. Raven Press New York, 1994, 1-14.

Estep JE, Lame MW, Morin D, Jones AD, Wilson DW, Segall HJ. $\left[{ }^{14} C^{!}\right.$ monocrotaline kinetics and metabolism in the rat. Drug Metab Dispos. 1991; 19:135139.

Freis ED, Papademetriou V. Current drug treatment and treatment patterns with antihypertensive drugs. Drugs 1996; 52:1-16.

Ferrari R, Ceconi C, Curello S, Cargnoni A, Alfieri O, Pardini A, Marzollo P, Visioli $O$. Oxygen free radicals and myocardial damage: protective role of thiol-containing agents. Am J Med. 1991; 91:95S-105S.

Ferrari R, Ceconi C, Curello S, Cargnoni A, De Guili F, Visioli O. Occurence of oxidative stress during myocardial reperfusion. Mol Cell Biochem. 1992; 11:61-69. 
Gerdes AM, Onodera T, Wang X, McCune SA. Myocyte remodeling during the progression to failure in rats with hypertension. Hypertension 1996: 28:609-614.

Grech ED, Jackson M, Ramsdale DR. Reperfusion injury after acute myocardial infarction. Br Med J. 1995; 310:477-478.

Gupta M, Singal P.K. Higher antioxidant capacity during chronic stable heart hypertrophy. Circ Res. 1989; 64:398-406.

Hauser GJ, Danchak MR, Colvin MP, Hopkins RA, Wocial B, Myers AK, Zukowska-Grojec $\mathbf{Z}$. Circulating neuropeptide $\mathbf{Y}$ in humans: relation to changes in catecholamine levels and changes in hemodynamics. Neuropeptides 1996; 30:159-165.

Hayashi Y, Lalich JJ. Renal and pulmonary alterations induced in rats by a single injection of monocrotaline. Proc Soc Expl Biol Med. 1967; 124:392-396.

Heilbron BG, Gin KG. Beta adrenoceptor blocking agents for the treatment of heart failure. Int J Clin Pharmacol Ther 1996; 34:231-235.

Hill M, Singal PK. Antioxidant and Oxidative Stress changes during heart failure subsequent to myocardial infarction in rats. Am J Pathol 1996; 148:291-300.

Hirono I. Natural carcinogenic products of plant origin. CRC Crit Rev Toxicol. $1981 ; 235-237$.

Hoffman RM, Garewal HS. Antioxidants and the prevention of coronary heart disease. Arc Inter Med. 1995; 155:241-246.

Honda M, Yamada S, Goto Y, Ishikawa S, Yoshikane H, Ishinaga Y, Kuzuo H, Morioka S, Moriyama K. Biochemical and structural remodeling of collagen in the right ventricular hypertrophy induced by monocrotaline. Jpn Circ J. 1992; 56:392403. 
Huxtable RJ. Activation and pulmonary toxicity of pyrrolizidine alkaloids. Pharmacol and Ther. 1990; 47:371-389.

Ishikawa K, Hashimoto H, Mitani S, Toki Y, Okumura K, Ito T. Enalapril improves heart failure induced by monocrotaline without reducing pulmonary hypertension in rats: roles of preserved myocardial creatine kinase and lactate dehydrogenase isoenzymes. Int J Cardiol. 1995; 47:225-233.

Ishikawa S, Honda M, Yamada S, Morioka S, Moriyama K. Biventricular downregulation of beta-adrenergic receptors in right ventricular hypertrophy induced by monocrotaline. Jpn Circ J. 1991; 55:1077-1085.

Kapelko VI, Popovich MI, Kupriyanov VV. Cardiac contractile failure caused by disturbances in myofibrillar energy supply and pathogenesis of cardiomyopathies. In Pathophysiology of heart failure. Kluwer academic publishers 1996. 127-138.

Kato M, Kinugawa T, Omodani H, Osaki S, Ahmmed GU, Ogino K, Hisatome I, Miyakoda H, Thames MD. Responses of plasma norepinephrine and reninangiotensin-aldosterone systsem to dynamic exercise in patients with congestive heart failure. J Card Fail 1996; 2:193-110.

Kaul N, Siveski-Iliskovic N, Hill M, Slezak J, Singal PK. Free radicals and the beart. J Pharmacol Toxicol Meth. 1993; 30:55-67.

Kentera D, Susic D. Zdravkovic M. Chronic Pulmonary hypertension. Comp Pathol Bull. 1973; 70:2-4.

Khaper N, Singal PK. Effects of afterload-reducing drugs on pathogenesis of antioxidant changes and congestive heart failure in rats. J Am Coll Cardiol. 1997; 29:856-861.

Kinugawa T, Ogino K, Kitamura H, Saitoh M, Omodani H, Osaki S, Hisatome I, Miyakoda H. Catecholamines, renin-angiotensin-aldosterone system, and atrial natriuretic peptide at rest and during submaximal exercise in patients with congestive heart failure. Am J Med Sci 1996; 312:110-117. 
Kiowski W, Sutsch G, Dossegger L. Clinical benefit of angiotensin-converting enzyme inhibitors in chronic heart failure. J Cardiovasc Pharmacol. 1996; 27: S19S24.

Kirshbom PM, Tapson VF, Harrison JK, Davis RD, Gaynor JW. Delayed right heart failure following lung transplantation. Chest. 1996; 109:575-577.

Kirshenbaum LA, Singal PK. Antioxidant changes in heart hypertrophy: significance during hypoxia-reoxigenation injury. Can J Physiol Pharmacol. 1992; 70:1330-1335.

Kirshenbaum LA, Singal PK. Increase in endogenous antioxidant enzymes protects hearts against reperfusion injury. Am J Physiol. 1993; 265:H484-H493.

Kleber FX, Wensel R. Current guidelines for the treatment of congestive heart failure. Drugs. 1996; 51:89-98.

von Krimpern C, Schoemaker RG, Cleutjens JPM. Angiotensin I converting enzyme inhibitors and cardiac remodelling. Basic Res Cardiol. 1991; 86:149-155.

Kobayashi H, Yoshimura Y, Suzuki H, Hosoda Y. Regional difference of capillaryto-fiber ratio in the heart. Basic Res Cardiol. 1994; 89:118-127.

Kornbrust DJ, Mavis RD. Relative susceptibility of microsomes from lung, heart liver kidney, brain and testes to lipid peroxidation: correlation with vitamin $E$ content. Lipids. 1980; 15:315-322.

Kuchel O, Cantin M, Boo N, Debinski W, Jasmin G, Genest J. Cathecolamine dopamine- $\beta$-hydroxylase and atrial natriuretic factor content in separate heart chambers of cardiomyopathic hamster. Life Sci. 1987; 41:2333-2338.

Kupriyanov VV, Lakomkin VL, Korchazhkina OV, Stepanov VA, Steinschneider AY, Kapelko VI. Cardiac contractile function, oxygen consumption rate and cytosolic phosphates during inhibition of electron flux by amytal-a $a^{3} I P-N M R$ study. Biochem Bioph Acta. 1991; 1058:386-399. 
Lafranconi WM, Ohkuma S, Huxtable RJ. Biliary excretion of novel pneumotoxic metabolites of the pyrrolizidine alkaloid, monocrotaline. Toxicon 1985: 23:983-992.

Lafranconi M, Huxtable RJ. Pyrrolizidines and the pulmonary vasculature. Rev Drug Metab Dug Int. 1981; 3:271-315.

Lame MW, Jones AD, Morin D, Segall HJ. Metabolism of $\left[{ }^{[4} \mathrm{Clmonocrotaline}\right.$ by isolated perfused rat liver. Drug Metab Disp. 1991; 19:516-524.

Leedle RA, Aust SD. The effect of glutathione on the vitamin $E$ requirement for inhibition of liver microsomal lipid peroxidation. Lipids. 1990; 25:241-245.

Lemoyen BF, Van Gossum A, Kurian R, Ostro M, Axler J, Jeejeebhoy KN. Breath pentane analysis as an index of lipid peroxidation: a functional test of vitamin $E$ status. Am J Clin Nutr. 1987; 46:267-272.

Liu P. Reappraisal of calcium channel blockers in heart failure. Can J Cardiol 1996; 12:9F-13F.

Lualdi JC, Goldhaber SZ. Right ventricular dysfunction after acute pulmonary embolism: pathophysiologic factors, detection and therapeutic implications. Am Heart J. 1995; 130:1276-1282.

Luchner A, Stevens TL, Borgeson DD, Redfield MM, Bailey JE, Sandberg SM, Heublein DM, Burnett JC Jr. Angiotensin II in the evolution of experimental heart failure. Hypertension 1996; 28:472-477.

Marklund SL. Pyrogallol autoxidation. Handbook of methods for oxygen radical research. Edited by RA Greenwald. Boca Raton, FL, CRC Press, 1995. 243-247.

Mattocks AR, Croswell S, Jukes R, Huxtable RJ. Identity of a biliary metabolite formed from monocrotaline in isolated perfused rat liver. Toxicon. 1991; 29:409-415. 
Mayrick B, Reid L. The effect of chronic hypoxia on pulmonary arteries in young rats. Exp Lung Res. 1981; 2:257-271.

McMahon WS, Holzgrefe HH, Walker JD, Mukherjee R, Arthur SR, Cavallo MJ, Child MJ, Spinale FG. Cellular basis for improved left ventricular pump function after digoxin therapy in experimental left ventricular failure. J Am Coll Cardiol 1996; 28:495-505.

Mill JG, Stefanon I, Leite CM, Vassalo DV. Changes in performance of the surviving myocardium after left ventricular infarction in rats with chronic myocardial infarction. Cardiovasc Res. 1990; 24:748-753.

Morgan HE, Baker KM. Cardiac hypertrophy: mechanical, neural and endocrine dependence. Circulation. 1991; 83:13-25.

Morioka S, Honda M, Ishikawa S, Ishinaga Y, Yano S, Tanaka K, Moriyama K. Changes in contractile and non-contractile proteins, intracellular $\mathrm{Ca}^{2+}$ and ultrastructures during the development of right ventricular hypertrophy and failure in rats. Jpn Circ J. 1992; 56:469-474.

Munzel T, Kurz S, Rajagopalan S, Thoenes M, Berrington WR, Thompson JA, Freeman BA, Harrison DG. Hydrdalazine prevents nitroglycerin tolerance by inhibiting activation of a membrane-bound NADH oxidase. A new action for an old drug. J Clin Invest 1996; 98:1465-1470.

Ng CV, Angus PW, Chabrial H, Chou ST, Amolda L, Morgan DJ, Smallwood RA. Right heart failure impairs hepatic oxygenation and theophylline clearence in rats. J Pharmacol Exp Ther. 1995; 273:1332-1336.

Norgaard A, Bjerregaard P, Baandrup U, Kjeldsen K, Reske-Nielsen E, Thomsen $\mathrm{PE}$. The concentration of the $\mathrm{Na}, \mathrm{K}$-pump in skeletal and heart muscle in congestive heart failure. Int J Cardiol. 1990; 26:185-190.

O'Keefe JH Jr, Lavie CJ Jr, McCallister BD. Insights into the pathogenesis and prevention of coronary artery disease. Mayo Clin Proc. 1995; 70:69-79. 
Olivetti G, Capasso JM, Sonnenblick EH, Anversa P. Side to side slippage of myocytes participates in ventricular wall remodeling acutely after myocardial infarction in rats. Circ Res. 1990; 67:23-24.

Okumura K, Yamada Y, Matsui H, Shinoda M, Naruse K, Toki Y, Hashimoto H, Ito T. Altered myocardial neurotransmitter and 1,2-Diacylglycerol concentrations in right ventricular hypertrophy and failure in rats. In Mechanisms of Heart Failure. Kluwer Academic Publishers, 1995, 51-62.

Orchard CH, Eisner DA, Allen DG. Oscillations of intracellular calcium in mammalian cardiac muscle. Nature. 1983; 304:735-738.

Packer M. Neurohormonal interactions and adapatations in congestive heart failure. Circulation. 1988; 77:721-730.

Paglia DE, Valentine WN. Studies on the quantitative and qualitative characterization of erythrocyte glutathione peroxidase. J Lab Clin Med. 1967: 70:158-169.

Palace V.P., Brown S.B. HPLC determination of tocopherol, retinol, dehydroretinol and retinyl palmitate in tissues of lake Char (Salvelinus namaycush) exposed to coplanar 3,3',4,4',5-pentachlorobiphenyl. Env Tox Chem. 1994, 13:473-476.

Pan LC, Wilson DW, Lame MW, Jones AD, Segall HJ. Cor Pulmonale is caused by monocrotaline and dehydromonocrotaline, but not by glutathione or cysteine conjugates of dihydropyrrolizine. Toxicol Appl Pharmacol. 1993; 118:87-97.

Parmley WW. Pathophysiology of congestive heart failure. Am J Cardiol. 1985; 55:9A-14A.

Rabinovitch M, Gamble WJ, Miettinen OS, Reid L. Age and sex influence on pulmonary hypertension of chronic hypoxia and on recovery. Am J Physiol. 1981; 240:H62-H72. 
Randhawa AK, Singal PK. Pressure overload-induced cardiac hypetrophy with and without dilation. J Am Coll Cardiol. 1992; 20:1569-1575.

Roberts JD, Jr, Roberts CT, Jones RC, Zapol WM, Bloch KD. Continious nitric oxide inhalation reduces pulmonary arterial structural changes, right ventricular hypertrophy, and growth retardation in the hypoxic newborn rat. Circ Res. 1995: 76:215-222.

Roth RA, Dotzlaf LA, Baranyi B, Kuo CH, Hook JB. Effect of monocrotaline ingestion on liver, kidney and lung of rats. Toxicol Appl Pharmacol. 1981; 60:193203.

Rubin LJ. Pathology and Pathophysiology of primary pulmonary hypertension. Am J Cardiol. 1995; 75:51A-54A.

Saeki Y, Kurihara S, Hongo K, Tanak E. Alterations in intracellular calcium and tension of activated ferret papillary muscle in response to step length changes. $J$ Physiol. 1993; 463:290-306.

Schultze AE, Gunaga KP, Wagner JG, Hoorn CM, Moorehead WR, Roth RA. Lactate dehydrogenase activity and isozyme patterns in tissue and bronchoalveolar lavage fluid from rats treated with monocrotaline pyrrole. Toxicol Appl Pharmacol. $1994 ; 126: 301-310$.

Schumacher C, Konigs B, Sigmund M, Kohne B, Schondube F, Vob M, Stein B, Weil $J$, Hanrath $P$. The ryanodine binding sarcoplasmic reticulum calcium release channel in nonfailing and in failing human myocardium. Naunyn Arch Pharmacol. 1995; 353:80-85.

Shimoni A, Maor-Kendler Y, Neuman Y. Verapamil-induced acute right heart failure. Am Heart J. 1996; 132:193-194.

Shubat PJ, Hubbard AK, Huxtable RJ. Dose-response relationship in intoxication by the pyrrolizidine alkaloid monocrotaline. J Toxicol Environ Health. 1989; 28:445460. 
Sies H, Murphy ME. Role of tocopherol in the protection of biological systems against oxidative damage. J Photochem Photobiol B Biol. 1991: 8:211-224.

Simoni A, Long CS, Dudley GA, Yue P, McElhinny J, Massie BM. Heart failure in rats causes changes in skeletal muscle morphology and gene expression that are not explained by reduced activity. Circ Res. 1996; 79:128-136.

Singal PK, Kapur N, Dhillon KS, Beamish RE, Dhalla NS. Role of free radicas in catecholamine-induced cardiomyopathy. Can J Physiol Pharmacol. 1982; 60:13901397.

Singal PK, Petkau A, Gerrard JM, Hrushovetz S, Foerster J. Free radicals in health and disease. J Mol Cell Biochem. 1988; 84:121-122.

Singal PK, Kirshenbaum LA. A relative deficit in antioxidant reserve may contribute in cardiac failure. Can J Cardiol. 1990; 6:47-49.

Singal PK, Dhalla AK, Slezak J, Singh N. Effects of different oxidative stress conditions in hypertrophied rat hearts. In the adapted heart. Raven press NY. 1994 141-146.

Singal PK, Dhalla AK, Singh N, Hill M,Thomas TP, Seneviratne CK. Antioxidants and the heart. In Patophysiology of heart failure. Eds. NS. Dhalla, Singal PK, Takeda N and Beamish RE. Kluwer Academic Publishers, Boston. 1995. 149-170.

Singh N, Dhalla AK, Seneviratne C, Singal PK. Oxidative stress and heart failure. Mol. Cell Biochem. 1995; 147:77-81.

Singh RB, Niaz MA, Rastogi SS, Rastogi S. Usefulness of antioxidant vitamins in suspected acute myocardial infarction (The indian experiment of infarct survival-3). Am J Cardiol. 1996; 77:232-236.

Siveski-Iliskovic N, Kaul N, Singal PK. Probucol promotes endogenous antioxidants and provide protection against adriamycin-induced cardiomyopathy in rats. Circulation. 1994; 89:2829-2835. 
Smith LW, Culvenor CCJ. Plant sources of hepatotoxic pyrrolizidine alkaloids. J Nat Prod. 1981; 41:129-152.

Stephens NG, Parsons A, Schofield PM, Kelly F, Cheeseman K, Mitchinsoon MJ. Randomised controlled trial of vitamin $E$ in patients with coronary disease: Cambridge Heart Antioxidant Study (CHAOS). Lancet 1996; 347:781-786.

Struthers $\mathrm{AD}$. Aldosterone escape during angiotensin-converting enzyme inhibitor therapy in chronic heart failure. J Card Fail 1996; 2:47-54.

Tak T, Soni R, Dave R, Chandraratna PAN, Chandrasoma P. Prolonged survival after masive pulmonary embolism in a patient with atrial septal defect and mass in the right ventricle. Can J Cardiol. 1996; 73:199-202.

Teerlink JR. Neurohumoral mechanisms in heart failure: a central role for the reninangiotensin system. J Cardivasc Pharmacol 1996; 27:S1-S8.

Tian R, Nascimben L, Kaddurah-Daouk R, Ingwall JS. Depletion of energy reserve via the creatine kinase reaction during the evolution of heart failure in cardiomyopathic hamster. J Mol Cell Cardiol. 1996; 28:755-765.

Todorovich-Hunter L, Dodo H, Ye C, McCready L, Keeley FW, Rabinovitch M. Increased pulmonary artery elastolytic activity in adult rats with monocrotalineinduced progressive hypertensive pulmonary vascular disease compared with infant rats with nonprogressive disease. Am Rev Respir Dis. 1992; 146:213-223.

Turner JH, Lalich JJ. Experimental Cor Pulmonale in the rat. Arch Path. 1965; 79:409-418.

Valdivia E. Right ventricular hypertrophy in guinea pigs exposed to simulated high altitude. Circ Res. 1957; 5:612-616.

van Veldhuisen DJ, de Graeff PA, Remme WJ, Lie KI. Value of digoxin in heart failure and sinus rhythm: new features of an old drug? J Am Coll Cardiol 1996; 28:813-819. 
Williams DE, Reed RL, Kedzierski B, Dannan GA, Guengerich FP, Buhler DR. Bioactivation and detoxication of the pyrrolizidine alkaloid senecionine by cytochrome P-450 enzymes in rat liver. Drug Metab Disp. 1989; 17:387-392.

Xiong L, Bouanani NE, Su JB, Crozatier B. Propranolol therapy in experimental heart failure in rabbits improves cardiac response to catecholamines without beta adrenoceptor up-regulation. Fundam Clin Pharmacol. 1995; 9:522-530.

Yan CC, Huxtable RJ. The relationship between the concentration of the pyrrolizidine alkaloid monocrotaline and the pattern of metabolites released from the isolated liver. Toxicol Appl Pharmacol. 1995; 130:1-8.

Yan CC, Huxtable RJ. Relationship between glutathione concentration and metabolism of the pyrrolizidine alkaloid, monocrotaline, in the isolated, perfused liver. Toxicol Appl Pharmacol. 1955b; 130:132-139.

Yelton SL, Gaylor MA, Murray KM. The role of continuous infusion loop diuretics. Ann Pharmacother 1995; 29:1010-1014.

Yoshie $\mathbf{H}$, Tobise $\mathrm{K}$, Onodera $\mathrm{S}$. Intraventricular changes in the $\boldsymbol{\beta}$-adrenoceptoradenylate cyclase system of the rat heart with the progress of monocrotaline-induced right ventricular hypertrophy. Jpn Circ J. 1994; 58:855-865.

Zhu L, Wigle D, Hnek A, Kobayashi J, Ye C, Zuker M, Dodo H, Keeley FW, Rabinovitch $M$. The endogenous vascular elastase that governs development and progression of monocrotaline induced pulmonary hypertension in rats is a novel enzyme related to the serine protease adipsin. J Clin Invest. 1994; 94:1163-1171. 